\title{
Institutional Corruption and Election Fraud: Evidence from a Field Experiment in Afghanistan
}

\author{
By Michael Callen and James D. Long*
}

\begin{abstract}
We investigate the relationship between political networks, weak institutions, and election fraud during the 2010 parliamentary election in Afghanistan combining: $(i)$ data on political connections between candidates and election officials; (ii) a nationwide controlled evaluation of a novel monitoring technology; and (iii) direct measurements of aggregation fraud. We find considerable evidence of aggregation fraud in favor of connected candidates and that the announcement of a new monitoring technology reduced theft of election materials by about 60 percent and vote counts for connected candidates by about 25 percent. The results have implications for electoral competition and are potentially actionable for policymakers. (JEL C93, D02, D72, K42, O17)
\end{abstract}

Many governments are not responsive to their citizens. Fair elections provide an important means of improving responsiveness by making elected officials accountable to voters. ${ }^{1}$ However, election fraud undermines this critical function in many young democracies, often at the hands of tightly networked groups of political elites. This paper examines whether candidates exploit connections to elections officials to add fraudulent votes during the aggregation process. We study this problem in

\footnotetext{
* Callen: Harvard Kennedy School, Harvard University, 79 JFK Street, Cambridge, MA 02138 (e-mail: michael_callen@hks.harvard.edu); Long: Department of Political Science, University of Washington, 1410 Northeast Campus Parkway, Seattle, WA 98195 (e-mail: jdlong@uw.edu). We are grateful to Glenn Cowan, Jed Ober, Eric Bjornlund, Evan Smith, and Jon Gatto at Democracy International (DI) and Nader Nadery, Jandad Spinghar, and Una Moore at the Free and Fair Elections Foundation of Afghanistan (FEFA). We acknowledge financial support from USAID Development Innovation Ventures (DIV), DI, and grant \#FA9550-09-1-0314 from the Air Force Office of Scientic Research (Callen). We are indebted to James Andreoni, Leonardo Bursztyn, Luke Condra, Gordon Dahl, Daniel Egel, Col. Joseph H. Felter, Ray Fisman, Tarek Ghani, Susan Hyde, Radha Iyengar, Danielle Jung, Asim Ijaz Khwaja, David Laitin, David Lake, Edward Miguel, Karthik Muralidharan, Paul Niehaus, Gerard Padró-i-Miquel, Rohini Pande, Ngoc Anh Tran, Maura O’Neill, Shanker Satyanath, Jacob Shapiro, Romain Wacziarg, Scott Worden, Christopher Woodruff, and seminar participants at the NBER Political Economy Meeting, the 2011 NEUDC conference, George Mason University, the Development and Conflict Research (DACOR) conference, the 2011 Institute on Global Conflict and Cooperation (IGCC) conference, UC San Diego, Yale, the Center for Global Development (CGD), and USAID for extremely helpful comments. We are particularly indebted to Eli Berman, Clark Gibson, and Craig McIntosh for advice and support at all stages of the project. This project would not have been possible without the dedicated research assistance of Randy Edwards, Mohammad Isaqzadeh, Shahim Kabuli, and Arman Rezaee. Mistakes remain with the authors. The authors declare that they have no relevant or material financial interests that relate to the research described in this paper.

Go to http://dx.doi.org/10.1257/aer.20120427 to visit the article page for additional materials and author disclosure statement(s).

${ }^{1}$ There is substantial empirical documentation of the benefits of improving political accountability (Besley and Burgess 2002; Besley, Pande, and Rao 2005; Chattopadhyay and Duflo 2004; Ferraz and Finan 2008, 2011; Fujiwara 2013; Pande 2003; Martinez-Bravo et al. 2013). Additionally, in countries experiencing violent contests for state control (such as Afghanistan), fair elections may also undermine popular support for insurgents by promoting an accountable and legitimate government and by providing a forum for reconciliation (Berman, Shapiro, and Felter 2011; Besley and Persson 2011; McChrystal 2009; United States Army 2006; World Bank 2011).
} 
Afghanistan, a country where democratic institutions are struggling to develop after the last three decades of continuous conflict. ${ }^{2}$

There are many ways to manipulate elections, including voter intimidation, ballot box stuffing, and changing vote totals after ballots are cast. We study the manipulation of vote totals during the aggregation process, which we henceforth call aggregation fraud. We are interested in this particular type of fraud because it is likely to involve collusion between candidates and election officials. We collect novel data on aggregation fraud by photographing provisional vote tally sheets at individual polling centers before the aggregation process and comparing these counts to the corresponding numbers after aggregation is completed. ${ }^{3}$ This technique, which we call photo quick count, records the same vote totals both before and after aggregation. In a clean election, these numbers should be identical. We find differences at 78 percent of the polling locations in our observed sample. Additionally, candidates connected to officials in charge of aggregation receive an average of 3.5 fraudulent votes per polling station (about 13.7 percent of their polling station average).

Given that fraud affects many elections in developing countries, there is reason to study the effects of election monitoring both for the design of policy and for understanding the mechanics of election fraud. We therefore implement an experiment both to estimate the causal effect of photo quick count on aggregation fraud and to provide more general evidence on the response of fraud to the credible threat of discovery through monitoring. Specifically, we test whether announcing photo quick count measurements to election officials reduces fraud. We deliver a letter to a randomly selected set of polling center managers in 238 polling centers from an experimental sample of 471 polling centers..$^{4}$ The letter explains how photo quick count works and announces that the measurement will be taken. Our nationwide experimental sample comprises 7.8 percent of polling centers operating on election day and spans 19 of Afghanistan's 34 provinces.

This experiment produces four main results. First, the photo quick count announcement reduced damaging of election materials by candidate representatives from 18.9 to 8.1 percent (a reduction of about 60 percent). Second, it reduced votes for politically powerful candidates at a given polling location from about 21 to about 15 (a reduction of about 25 percent) .5 Treatment effects are also larger for candidates connected to officials in charge of aggregation in their constituency. ${ }^{6}$ These candidates lost about 6.5 votes as a result of the intervention. ${ }^{7}$ Third, the intervention impacts fraud measured directly using photo quick count. Point estimates for this effect

\footnotetext{
${ }^{2}$ Rashid (2009) provides an authoritative account of how the patronage networks of Afghan warlords have undermined political development in Afghanistan.

${ }^{3}$ In many countries, it is standard for election officials to record vote totals at a particular polling center on an election returns form and then post the form on the outside of the polling center, indicating vote totals at the polling centers to local residents.

${ }^{4}$ Polling center managers are election officials tasked with managing the voting process on election day and overseeing the counting of votes at the end of the day in their assigned polling center.

${ }^{5}$ The mean number of votes cast for a candidate at a given polling substation in our control sample is 1.41 , reflecting the fact that many candidates receive no votes in many locations. The mean number of votes cast for all candidates at a given polling location is 269 .

${ }^{6}$ As we describe in Section II, we observe these connections only for 57 candidates, a small subset of candidates running in the election. In online Appendix Table A2, however, we find that treatment effects are localized to connected candidates, even controlling for whether they were investigated.

${ }^{7}$ Correspondingly, these candidates receive enough votes to rank among winning candidates at 49.7 percent of the polling substations in our control sample. Our treatment reduces this share to 38.2 percent of polling substations.
} 
range between 9.37 and 17.17 fewer votes changed during aggregation for candidates connected to the provincial aggregator. ${ }^{8}$ Last, we find that having a neighbor treated within one kilometer $(\mathrm{km})$ is associated with an additional reduction of about seven votes, suggesting our estimates may slightly understate the true effect.

Our results relate to empirical findings in four strands of literature on the economics of corruption. First, as in the important examples provided by Bertrand et al. (2007) and Olken and Barron (2009), we find that corruption limits the ability of governments to correct externalities. The purpose of electoral law is to ensure that election outcomes reflect the will of the electorate. We show that this function is undermined by a faulty aggregation process. Second, the effects of announcing photo quick count depend on preexisting connections between candidates and election officials. Fragile democracies provide many examples of elected officials sharing rents with their networks (Fisman 2001; Khwaja and Mian 2005). Free and fair elections may place limits on this (see, for example, Ferraz and Finan 2008, 2011), and so patronage networks might have incentives to coordinate when capturing elections. This suggests the possibility of multiple equilibria in corruption as discussed in Olken and Pande (2011); the same intervention can have very different effects depending on preexisting political relationships. Third, we examine the determinants of equilibrium patterns of corruption (Shleifer and Vishny 1993; Cadot 1987; Rose-Ackerman 1975; Svensson 2003), focusing on the role of candidate connections. Last, our experiment relates to the growing body of experimental and quasi-experimental assessments of initiatives to improve elections (Aker, Collier, and Vicente 2013; Fujiwara 2013; Hyde 2007; Ichino and Schündeln 2012). Our project also draws direct inspiration from work in development economics on efforts to improve transparency and accountability (Niehaus et al. 2013; Duflo, Hanna, and Ryan 2012; Di Tella and Schargrodsky 2003; Ferraz and Finan 2008; Olken 2007; Yang 2008).9

We point to three implications for policies aimed at strengthening democratic institutions. First, aggregation fraud was a serious problem in this election. When electoral institutions are weak, candidates may be able to leverage their ties to officials to distort electoral outcomes in their favor. Second, we find a substantial response of fraud to monitoring, suggesting that monitoring can increase fairness in elections. Third and relatedly, our results provide promise for photo quick count as a means of both precisely measuring and of reducing aggregation fraud. This approach can increase precision beyond existing forensic tests which compare realized vote distributions with theoretical distributions that should occur in a fair election. ${ }^{10}$ Moreover, such checks can be subverted by competent manipulators by ensuring that rigged values follow the test distributions. The technology is also highly compatible with implementation via Information Communications Technology. The cost of recording and centralizing information on diffuse illegal behavior is now nominal. The rapid increase in cellular connectivity and in smartphone usage in developing

\footnotetext{
${ }^{8}$ These large bounds on the estimated treatment effect are due to substantial treatment-related attrition in this measure. We calculate these bounds using the trimming method of Lee (2009).

${ }^{9}$ Research on the role of monitoring and anti-corruption efforts in development is advancing rapidly; we direct readers to Olken and Pande (2011) and McGee and Gaventa (2011) for excellent reviews of research in this field.

${ }^{10}$ Myagkov, Ordeshook, and Shakin (2009); Mebane (2008); and Beber and Scacco (2012) describe forensic methods of detecting election fraud.
} 
countries allows the possibility that this technology might also be adapted to citizen-based implementation.

We structure the rest of the paper as follows. Section I describes our experimental setting and relevant features of electoral institutions in Afghanistan. Section II presents results using data on directly measured aggregation fraud. Section III describes our experimental evaluation of photo quick count. Section IV provides results from the experiment and Section V concludes.

\section{Institutional Background}

\section{A. Post-Invasion Democracy in Afghanistan}

After the invasion by the United States and fall of the Taliban in 2001, a coalition of international armed forces helped to empanel a Constitutional Loya Jirga to establish democratic institutions in Afghanistan after decades of internecine conflict, civil war, and Taliban rule. In 2004, popular elections validated the Loya Jirga's choice of Hamid Karzai as president, and in 2005, Afghans voted in the first elections for the lower house of parliament (Wolesi Jirga). In 2009, Karzai was reelected amid claims of rampant election fraud, which largely discredited the government. ${ }^{11}$ Afghans returned to the polls in September 2010 to elect members of parliament amid a growing insurgency and a US commitment to begin withdrawing troops in July 2011. The international community viewed these elections as a critical benchmark in the consolidation of democratic institutions given doubts about the Karzai government's ability to exercise control in much of the country. Despite lingering memories of violence and widespread fraud from the 2009 election, roughly 5 million voters cast ballots in the 2010 Wolesi Jirga elections. ${ }^{12}$

\section{B. Electoral Institutions}

Three features of the parliamentary election system in Afghanistan make it particularly vulnerable to fraud. First, many seats are available within a single constituency, creating thin victory margins for a large number of positions. This both makes fraudulent votes highly valuable and also increases the number of potential manipulators. Second, electoral institutions in Afghanistan are just beginning to develop but remain weak. Finally, the state exercises incomplete territorial control, leaving polling centers in contested regions vulnerable to closure or capture. We discuss each of these three features in this section.

Afghanistan's 34 provinces serve as multi-member districts that elect members to the Wolesi Jirga. Each province serves as a single electoral district and the number of seats it holds in parliament is proportional to its estimated population. Candidates

\footnotetext{
${ }^{11}$ Karzai initially won 53 percent of the vote, above the 50 percent threshold necessary to avoid a run-off. After an independent investigation based on physical inspections of a random subsample of ballots, Karzai's share was reduced to 47 percent. Karzai finally won reelection when his main competitor, Abdullah Abdullah, refused to participate in the run-off.

${ }^{12}$ The Independent Electoral Commission projected this number out of what it believes are 11 million legitimate registered voters. Afghanistan has never had a complete census so population estimates vary widely. The total population is estimated at roughly 30 million and the voting age population is roughly 16 million.
} 
run at large within a province without respect to any smaller constituency boundaries. Voters cast a Single Non-Transferable Vote (SNTV) for individual candidates, nearly all of whom run as independents. ${ }^{13}$ The rules declare winning candidates as those who receive the most votes relative to each province's seat share. For example, Kabul province elects the most members to Parliament (33), Ghor province elects the median number of candidates in our sample (6), and Panjsher the fewest (2). The candidates who rank 1 to 33 in Kabul, 1 to 6 in Ghor, and 1 to 2 in Panjsher win seats. 14

This method for allocating seats in parliament for winning candidates provides incentives for fraud. Because many seats are available within a single province, a large number of candidates gain office with thin victory margins. SNTV with large district magnitudes and a lack of political parties also disperses votes across many candidates. The vote margin separating the lowest winning candidate from the highest losing candidate is often small. This creates a high expected return for even small manipulation for many candidates. In contrast, electoral systems with established parties and with small district magnitude tend to produce larger victory margins, so nonviable candidates may be less likely to rig. Because each province contains multiple seats, it remains possible for election officials involved in vote aggregation to rig votes on behalf of multiple officials simultaneously.

Electoral malfeasance in Afghanistan may also be partly due to the weak institutions tasked with managing elections. The Independent Election Commission serves as the main electoral body responsible for polling, counting votes, aggregation, and certifying winning candidates. Historically, the Independent Election Commission has proven susceptible to influence by corrupt agents. We review specific features of the aggregation process which conduce to fraud and considerable photographic evidence of fraud in Section II below. 15

Informal networks also play an important role in determining political outcomes in Afghanistan. Despite attempts to promote democratic institutions, preexisting power structures remain highly relevant. ${ }^{16}$ For example, several of the main candidates in the 2010 election and a number of current government officials were warlords prior to the US-led invasion. Former warlords also had considerable influence during the drafting of the Bonn Agreement, which provides the basis for Afghanistan's current political institutions. Along these lines, Karzai enjoys strong links with government officials in Southern Afghanistan given his family roots in that part of the country. Former warlords fighting in the Northern Alliance against the Taliban exert strong control in Northern Afghanistan and have played a key role in the US-backed government.

Despite weak electoral institutions, candidates and officials face some possibility of punishment for rigging. The Electoral Complaints Commission, which is

\footnotetext{
${ }^{13}$ SNTV systems provide voters with one ballot that they cast for one candidate when multiple candidates run for multiple seats. If a voter's ballot goes toward a losing candidate, the vote is not reapportioned. Although this electoral system is rare, former US ambassador to Afghanistan Zalmay Khalilzad and President Hamid Karzai promoted SNTV during the first parliamentary elections in 2005 to marginalize warlords and reduce the likelihood they obtained parliamentary seats. As a corollary, Karzai also decreed that political parties should not be allowed to form.

${ }^{14}$ There are 249 seats in the Wolesi Jirga. Ten seats are reserved for the nomadic Kuchi population and the remaining seats are allocated in proportion to the estimated population of the province.

${ }^{15}$ Similarly, Callen and Weidmann (2013) find that fraud was sufficiently severe to be detected by relatively insensitive forensic techniques in about 20 percent of the 398 districts in Afghanistan.

${ }^{16}$ For example, the Afghan attorney general, Ishaq Malako alleged in an address to parliament, broadcast on Afghan nation television, that election outcomes were heavily influenced by well-connected Afghans through secret dealings in Dubai, and claimed to have evidence to that effect.
} 
backed by the United Nations, exists as a separate and independent body from the Independent Elections Commission. The Electoral Complaints Commission investigates complaints against polling officials, candidates, or citizens. Any Afghan can lodge such a complaint. Based on the seriousness of a complaint and its likelihood of affecting the election's outcome, the Electoral Complaints Commission may decide to cancel all of the votes at a given polling location, all of the votes for a particular candidate at a polling location, or the total votes for a candidate across their entire constituency. The Electoral Complaints Commission overturned some 25 percent of the ballots in this process in the 2010 election. This resulted in 30 seats changing hands (National Democratic Institute 2010). Additionally, under its purview of fighting corruption, the attorney general's office may prosecute specific individuals, including election officials and candidates, it believes to have participated in election fraud and levy fines or prison sentences against them if found guilty. ${ }^{17}$

\section{Aggregation Fraud}

There are many ways to rig an election such as buying votes, intimidating voters, and stuffing ballot boxes. We focus on fraud which happens during the aggregation process. This type of fraud typically involves adjusting votes in favor of a particular candidate and usually happens at a central aggregation center.

We capture vote totals both immediately before and directly after the aggregation process, which took roughly one month. These data directly measure votes added or subtracted during aggregation for each candidate at each polling location in our observed sample. To our knowledge, these are the first direct measurements of aggregation fraud. We begin by examining which types of candidates benefit from aggregation fraud and summarize a few basic patterns.

\section{A. Vote Aggregation}

Aggregation takes place in three stages. First, after voting concludes, election staff count votes at individual polling centers. Polling centers contain several polling substations. There are typically four substations in a polling center. For example, a polling center might be a school, and polling substations are classrooms set up as polling locations inside of the school. ${ }^{18}$ Counting is overseen at each polling center by a polling center manager. The candidate totals for each substation are recorded on a single Declaration of Results form. Second, copies of the results forms are then sealed in a tamper-evident bag and sent to a Provincial Aggregation Center. After the

\footnotetext{
${ }^{17}$ To our knowledge, no candidates received criminal penalties for committing election fraud. However, during the month-long aggregation process, the attorney general attempted to suspend the heads of both the Independent Election Commission and the Electoral Complaints Commission.

${ }^{18}$ Analysis in this paper is done at the level of the polling substation. In particular, we use votes for a given candidate at a single polling substation as a main outcome. We had several options in terms of the level of aggregation to select as the unit of analysis. The candidate-polling substation is the most basic constitutive unit. We use this as the unit of analysis because polling substation outcomes range much less widely than polling center outcomes. This allows us to estimate treatment effects across fairly similar units. In our data, there are between 1 and 11 polling substations in a given polling center. The number of votes cast at a polling substation varies between 0 and 599 , reflecting a law that when 600 votes are cast, a new substation must be opened. By contrast, the number of votes cast at a polling center in our data ranges from 0 to 5,526. Online Appendix Table A8 reports results aggregating to the candidate-polling center level.
} 


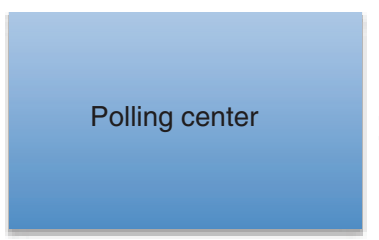

Presiding official:

Polling center manager

Total number: 6,038

Period of operation:

7AM-4PM on election day

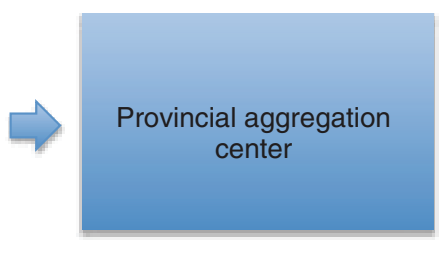

Presiding official:

Provincial elections officer

Total number: 34

Period of operation:

$\sim 1$ month after election

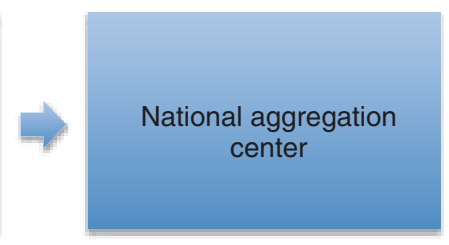

Presiding official:

Chairman

Total number: 1

Period of operation:

$\sim 3$ month after election

Figure 1. The Aggregation Process

count, the ballots are returned to the boxes, and the boxes are stored locally and are not transmitted to the Provincial Aggregation Center. ${ }^{19}$ Changing the Declaration of Results forms is therefore all that is necessary to manipulate the aggregation process. Separate copies of each Declaration of Results form are also posted on the outside of the polling center for public viewing. One Declaration of Results form is posted for each polling substation. In the final stage, results forms are collected at the National Aggregation Center in Kabul and combined to produce a national total. Figure 1 summarizes the aggregation process.

\section{B. Measuring Fraud}

We measure fraud by taking photographs of the Declaration of Results form posted for public viewing prior to aggregation and comparing this record to the corresponding vote total after aggregation. We compare at the level of individual candidates at specific polling substations. Figure 2 illustrates the method. Our research team took the picture on the left at a polling center in the field the morning after election day. The scan on the right was taken at the national aggregation center in Kabul about one month later. The picture on the right should be of a carbon paper copy of the form on the left and so they should be identical. Nonetheless, we find three major differences.

First, someone has converted the Dari script for the polling center and polling substation numbers into arabic numerals. Second, the name of the polling center manager has changed. Last, the sheet on the left records votes for several candidates and appears to result from normal polling while the figure on the right records no votes whatsoever.

To record these differences we require both a picture and post-election data on votes disaggregated by candidate and polling substation. We obtained postelection data by scraping the election commission website on October 24, 2010.20 Pre-aggregation vote totals are based on photographs. We hand-coded 48,871 vote entries for 1,784 different candidates at 347 polling substations directly from our

\footnotetext{
${ }^{19}$ In most cases, boxes are stored at one pre-designated site in each of the 398 districts across Afghanistan.

${ }^{20}$ Web scraping involves collecting, downloading, and structuring .html data which is available on the Internet but not in a form ready for analysis. We obtained the earliest possible returns in order to isolate the effects of our treatment from the many readjustments that were made during a year long arbitration process.
} 
Panel A. Election returns form at the polling center

Panel B. Election returns form at the

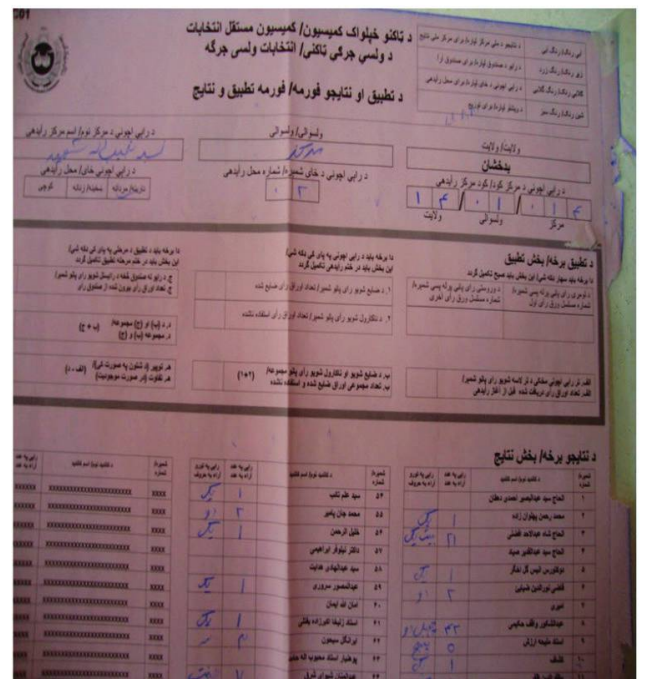

national aggregation center

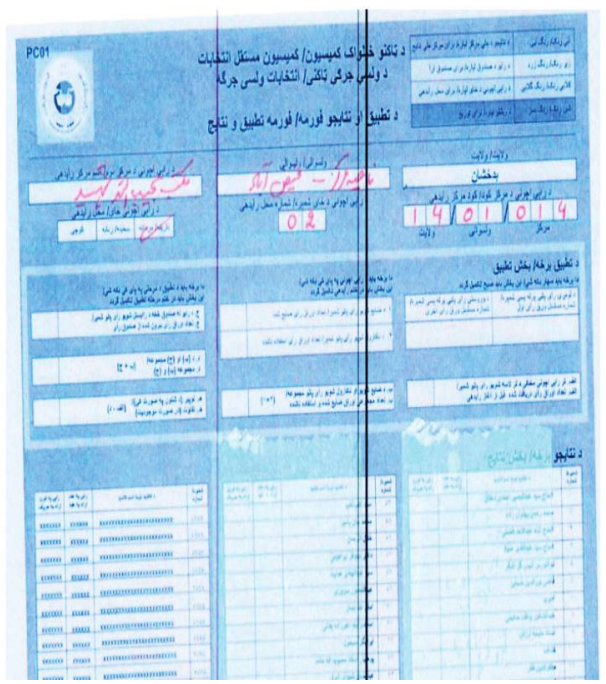

Figure 2. Election Returns Form for the Same Polling Center before and after Aggregation

photographs. ${ }^{21}$ Of these observations, we have corresponding data from our web scrape for 48,018 entries at 346 polling substations. These 346 polling substations were contained in 149 distinct polling centers in our experimental sample. ${ }^{22}$

\section{Patterns of Fraud}

There are several ways a candidate might adjust votes during the aggregation process. They might simply add votes to their total without adjusting votes for other candidates. Alternatively, they might cancel votes for competitors or move votes from their competitors' total to their own total. To gain a sense of how this is done, we examine whether votes are only added, subtracted, or some combination across all candidates on a given Declaration of Results form. Table 1 describes the frequency of five different patterns of fraud.

In the majority of cases ( 36.7 percent), candidates add votes while simultaneously subtracting from competitors. Candidates also commonly add votes, while leaving their competitors' totals unaltered (20.2 percent of cases). Adding and subtracting in equal measure is less common (4.3 percent of cases) as is simply subtracting votes (4.3 percent of cases). ${ }^{23}$ Only 21.4 percent of the polling substations in our sample record no change whatsoever, indicating the extent of aggregation fraud. Along these lines, of the 48,018 candidate-polling substation observations, 5,308

\footnotetext{
${ }^{21}$ We had data for 20 percent of our polling stations independently double-entered to try to minimize error associated with varying picture quality. During double entry we found mistakes for only five candidate-polling substation observations.

${ }^{22}$ In three of the polling centers (five polling substations) in our data, we record no votes after aggregation. This might signal that the Independent Elections Commission officially canceled votes from these polling centers, or that a candidate successfully managed to eliminate all votes from these polling centers during aggregation. Our results are robust to dropping these three polling centers.

${ }^{23}$ The five polling substations that record no positive votes for any candidate after aggregation fall into the subtracting votes only category.
} 
Table 1-Aggregation Discrepancy Patterns

\begin{tabular}{lccr}
\hline \hline & $\begin{array}{c}\text { Number of polling substations } \\
\text { Pattern }\end{array}$ & $\begin{array}{c}\text { Share of sample } \\
(2)\end{array}$ & $\begin{array}{c}\text { Mean vote difference } \\
(3)\end{array}$ \\
\hline No fraud & 74 & 21.4 percent & 0.00 \\
Adding votes only & 70 & 20.2 percent & 47.34 \\
Subtracting votes only & 15 & 4.3 percent & -245.07 \\
Adding and subtracting equally & 15 & 4.3 percent & 0.00 \\
Adding more than subtracting & 127 & 36.7 percent & 83.45 \\
Subtracting more than adding & 45 & 13.01 percent & -54.13 \\
\hline
\end{tabular}

Notes: This table reports aggregation discrepancy patterns. Each row corresponds to whether discrepancies during aggregation, across all candidates on the ballot at a given polling substation, reflect: (i) no change; (ii) only additions; (iii) only subtractions; (iv) additions and subtractions in equal measure; (v) more added votes than subtracted votes; or (vi) more subtracted votes than added votes. The sample comprises 341 polling substations for which both pre-aggregation and post-aggregation data are available. Column 1 reports the number of polling substations falling into each category. Column 2 provides the corresponding share of the total sample. Column 3 reports the average of vote differences across polling substations in the indicated category, where differences are calculated for each polling substation as the sum of differences between post-aggregation votes and pre-aggregation votes across all candidates on the ballot at the substation.

(11.05 percent) record some difference during aggregation. We note that we observe only a highly selected sample. ${ }^{24}$

\section{Political Connections and Aggregation Fraud}

Political connections between candidates and officials in charge of aggregation may facilitate fraud. To alter Declaration of Results forms, candidates need some means of accessing them. We examine whether votes for politically connected candidates are more likely to be altered using data on political connections from systematic investigations of candidates' political histories. These investigations involved extensive expert interviews in the relevant constituencies and crossvalidation against a set of additional resources. Online Appendix A.1 describes the investigation process in detail.

To examine the role of connections, we run regressions of the form

$$
Y_{i j s}=\beta_{0}+\beta_{1} \text { Investigated }_{i}+\beta_{2} \text { Connection }_{i}+\gamma_{j}+\varepsilon_{i s} .
$$

$Y_{i j s}$ is the difference in the number of votes before and after aggregation for can-

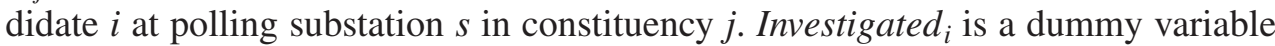
equal to 1 if the candidate is among the 57 candidates for whom we have political history data, Connection ${ }_{i}$ is a dummy variable equal to 1 for a political connection for candidate $i$ and $\gamma_{j}$ are constituency (province) fixed effects. ${ }^{25}$ We consider connections to President Karzai and to district and provincial aggregators. We also check whether votes for incumbents and for candidates with some government service are more likely to be altered. Table 2 provides summary statistics for the data used in these regressions.

\footnotetext{
${ }^{24}$ As we discuss in Section IV, at many polling substations these records were either not posted, torn down, or removed. If sheets are removed from polling centers where candidates anticipate adding votes, our data will report less fraud than actually occurred during the election.

${ }^{25}$ The political connection variables are based only on the investigations data, therefore $\beta_{2}$ is interpreted as the additional difference associated with connection $_{i}$, conditional on being investigated.
} 
Table 2-Summary Statistics on Political Connections and Aggregation Fraud

\begin{tabular}{lccc}
\hline \hline Variable & Mean & SD & Obs. \\
\hline Political connections & & & \\
Connected to provincial aggregator $(=1)$ & 0.005 & 0.073 & 48,008 \\
Connected to provincial + district aggregator $(=1)$ & 0.004 & 0.065 & 48,008 \\
Karzai connection (= 1) & 0.011 & 0.106 & 48,008 \\
Government service (=1) & 0.015 & 0.12 & 48,008 \\
Incumbent (= 1) & 0.067 & 0.25 & 48,008 \\
& & & \\
Aggregation fraud & & & \\
Post-aggregation votes - pre-aggregation votes & 0.166 & 6.409 & 48,008 \\
(Post-aggregation share - pre-aggregation share) $\times 100$ & 0.570 & 14.287 & 48,008 \\
\hline
\end{tabular}

Notes: This table reports summary statistics for political connections and for aggregation fraud. The unit of observation is the candidate-polling substation. The first five rows are dummy variables that equal 1 for each observation where a candidate has a connection of the indicated type. The penultimate row is the difference between post-aggregation and pre-aggregation votes. The last row is the difference between the post-aggregation and the pre-aggregation share multiplied by 100 . Both the pre-aggregation and the post-aggregation vote shares are calculated using pre-aggregation polling station totals as the denominator.

Table 3 reports results on the relationship between political connections and the degree of aggregation fraud. Vote totals for elite candidates are more likely to change during aggregation. In column 1 of panel A we see that votes for the 57 investigated candidates increase by an average of 1.870 votes during aggregation. In column 2 , we see that the votes for investigated candidates also connected to the provincial aggregator increase by a total of 2.552 votes. We reject that the sum of these coefficients equal zero with 95 percent confidence. Column 3 shows that candidates with a connection to the provincial aggregator and district aggregator add about 3.587 votes at each polling substation. None of our 57 investigated candidates are connected to the district aggregator but not the provincial aggregator, so we cannot estimate separate coefficients. Columns 4 and 5 show that connections to President Karzai and having a history of government service negatively predict vote addition, conditional on being in the investigated set, though these estimates are quite imprecise. Column 6 shows that incumbency, after accounting for investigation, has only a small additional effect. In column 6 we see that having a connection to the aggregator remains important, with the coefficient close to that reported in column 2, even after controlling for incumbency. We calculate standard errors for these estimates using the method of Cameron, Gelbach, and Miller (2011), which allows for arbitrary correlation for a given candidate across polling centers and across candidates within a given polling center. ${ }^{26}$

Panel B repeats this analysis replacing the dependent variable with the change in vote shares during aggregation. ${ }^{27}$ Being in the set of elite candidates with a political history investigation predicts the roughly 3 percent increase in vote share across specifications. To provide a sense of the magnitude, if a candidate moved from a

\footnotetext{
${ }^{26}$ In this case, these standard errors are more conservative than those clustered only at the candidate or only at the polling substation level.

${ }^{27}$ For both the pre-aggregation and post-aggregation vote share, we normalize votes by the total number of votes cast at the substation prior to election. We do this to isolate vote changes that are sure to benefit the candidate in question.
} 
Table 3-Vote Changes during Aggregation by Candidate Type

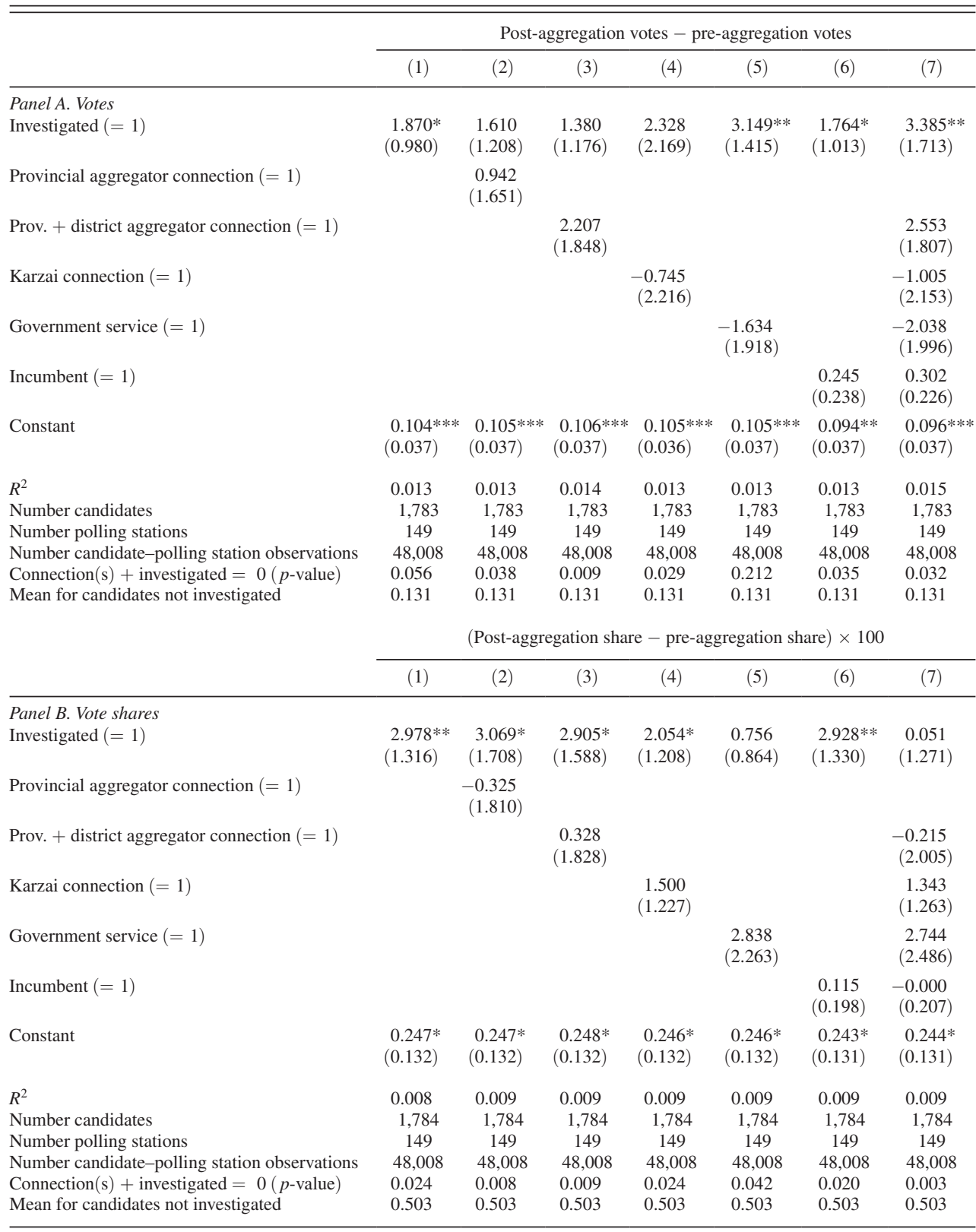

Notes: This table reports on political connections and the degree of aggregation fraud. The unit of observation is the candidate-polling substation. Each column in panel A reports results from an OLS regression using the difference between post-aggregation and pre-aggregation votes as the dependent variable and a dummy variable that equals 1 if a candidate-polling substation observation records the indicated connection(s) as an independent variable and an additional dummy that equals 1 if that observation has any background investigation data. Note that we observe connections only for investigated candidates. Panel B repeats these specifications using the difference between pre-aggregation and post-aggregation vote shares (multiplied by 100) as a dependent variable. Both pre-aggregation and post-aggregation vote shares are calculated using pre-election polling station vote totals as the denominator. All specifications in both panels include province fixed effects and drop the five largest and five smallest observations of the dependent variable. No candidates record a connection to the district aggregator and not to the provincial aggregator so these coefficients cannot be estimated separately. Sample: treatment and control polling centers for which complete vote difference data are available. Table A7 reports corresponding results for the control sample only. Levels of significance: Standard errors clustered by candidate and by polling center using the method of Cameron, Gelbach, and Miller (2011) are reported in parentheses.

*** Significant at the 1 percent level.

** Significant at the 5 percent level.

* Significant at the 10 percent level. 
0.5 percent vote share (the mean among uninvestigated candidates) to a 3.5 percent vote share, they would move from the seventh percentile to the seventy-ninth percentile of candidates receiving positive votes. ${ }^{28}$

While there is evidence that political strength predicts adding votes during aggregation, we treat this exercise speculatively for three reasons. First, we have data on connections only for the most powerful candidates. Political power is likely to be highly asymmetrically distributed across candidates and is concentrated in the subsample of 57 that we observe, making it difficult to determine precisely which type of connection is most important for rigging an election. ${ }^{29}$ Second, connections are likely correlated with other candidate attributes that facilitate fraud, and we observe only a very limited number of candidate characteristics making it difficult to rule out omitted variables. Last, we omit the five largest and smallest observations of the left-hand-side variable. These results are robust to dropping all but the three most negative observations, which are all at least 28.5 standard deviations away from the mean, but break down if these three outliers are included.

Our results, to this point, are based on a comparison of independent photographic records of election returns forms prior to aggregation and ex post results. ${ }^{30}$ This approach uncovers a type of fraud which is usually largely hidden, suggesting that it might also be used to deter manipulation. We now turn from a descriptive analysis of the dynamics of aggregation fraud to an examination of whether awareness of photo quick count can be used to reduce fraud.

\section{Experiment}

This section reports results from an experiment that randomly informed election officials about photo quick count measurements in order to assess potential impacts on fraud. This section describes the experimental setting, the information intervention used to manipulate the awareness of polling officials, and provides details of our treatment assignment protocol. Section IV describes our measures of election fraud and provides results.

\section{A. Experimental Setting}

During the period of our study, Afghanistan was an active warzone. To keep our field staff safe, we selected polling centers that met three safety criteria: (i) achieving the highest security rating given by the International Security Assistance Force (ISAF) and the Afghan National Police (ANP); (ii) being located in a provincial

\footnotetext{
${ }^{28}$ On average, there are 483 candidates listed at each of the polling substations in our sample and 93 candidates listed if we exclude Kabul from the sample. At a given polling substation, on average 267.701 votes are cast (standard deviation $=175.410)$. Excluding Kabul from the sample, on average 293.683 votes are cast (standard deviation $=178.285$ ).

${ }^{29}$ Online Table A6 reports regressions of vote changes during aggregation on specific connections only within the sample of investigated candidates.

${ }^{30}$ This design builds on Parallel Vote Tabulations (PVTs), which have been in use since the 1980s. Through representative sampling and recording of ballots by field staff, PVTs predict national totals within a small margin of error (Estok, Nevitte, and Cowan 2002), but do not make polling center specific comparisons. Two important technological developments allow us to build on the PVT concept. First, it is now common for election commissions to post disaggregated results on the Internet. Second, the cheap availability of digital photography allows rapid and accurate recording of returns forms.
} 
Panel A. National sample

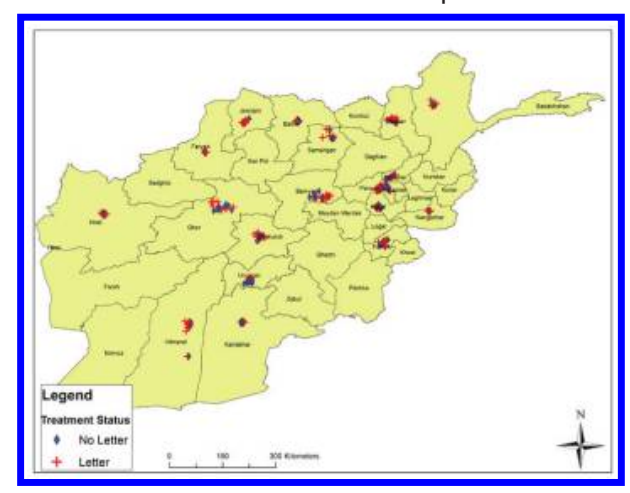

Panel B. Kabul subsample

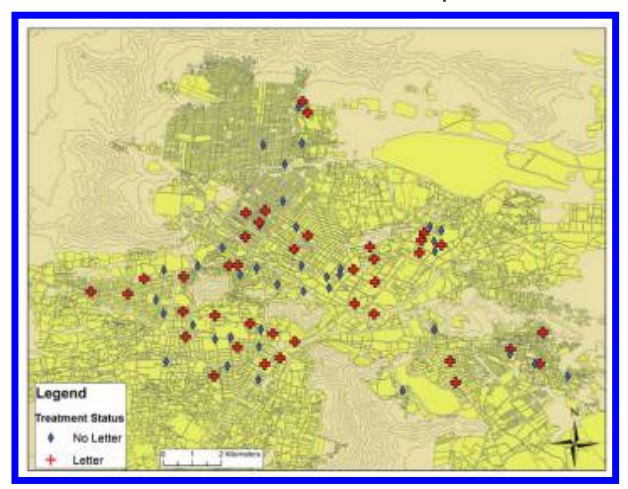

Figure 3. Experimental Sample of Polling Centers

center, which are much safer than rural areas; and (iii) being scheduled to operate on election day by the Independent Elections Commission. Figure 3 maps the polling centers in our national sample in panel A and in Kabul only in panel B. Our experimental sample comprises 471 polling centers $(7.8$ percent of polling centers operating on election day) in 19 of the 34 provincial capitals in Afghanistan.

\section{B. Experimental Intervention}

On election day (September 18, 2010) we randomly announced the use of photo quick count by delivering letters to 238 of the 471 polling centers in our experimental sample. We call this treatment our Letter Treatment. Online Appendix Figure A4 provides an English translation of the letter and online Appendix Figure A5 provides the Dari translation. We instructed our Afghan field staff to deliver letters to polling center managers after 10AM and before polling concluded at 4PM. Staff visited all 471 polling centers the following day in order to take a picture of the election returns form. ${ }^{31}$

The letter announced to polling center managers that researchers would photograph declaration of results forms the following day (September 19) in order to document discrepancies arising during aggregation. Two points about the experimental protocol bear emphasis. First, if we had not notified managers of monitoring on election day, they would have been unaware of our treatment as no election staff should be present at the polling center on the day after the election. Correspondingly, our staff report encountering election officials while they were taking photographs on the day following the election at only 2 of our 471 polling centers. Second, the experimental sample was known only to the research team. Polling center managers in the treatment group were informed of their status, but no election officials had a means of determining which sites we had selected as controls.

We asked polling center managers to acknowledge receipt by signing the letter. Managers at 17 polling centers ( 7 percent of centers receiving letters) refused to sign. We designate a polling center as treated if the manager received a letter (Letter

\footnotetext{
${ }^{31}$ Declaration of Returns forms were posted at the conclusion of the count around 9PM on election day. We determined that keeping our field staff out this late was unsafe and so we instructed them to return the following morning.
} 
Treatment $=1$ ). Our results remain robust to redefining treatment as both receiving and signing a letter.

\section{Assigning Treatment}

To inform our treatment assignment, we fielded a baseline survey of households living in the immediate vicinity of 450 of the polling centers in our experimental sample a month before the election (August 2010). On election day, we added 21 polling centers in Kabul after obtaining additional funding. ${ }^{32}$ We do not have baseline survey data for these 21 polling centers and so place them all in a single strata when assigning treatment. ${ }^{33}$

To ensure balance, we stratify treatment on province. In the 450 polling centers for which we have baseline data, we also stratify on the share of respondents from the baseline survey reporting at least occasional access to electricity and on respondents reporting that the district governor carries the most responsibility for keeping elections fair. We estimate all core specifications both with and without stratum fixed effects. ${ }^{34}$ Table 4 reports summary statistics and verifies balance and provides summary statistics for the remaining variables used in the analysis. ${ }^{35}$

\section{Data and Results}

We examine the impact of announcing photo quick count on four outcomes. The first is the direct aggregation fraud measure discussed in Section II, which we construct as the absolute value of the difference between votes before and after the aggregation process. This measure is subject to substantial nonrandom attrition, potentially biasing our estimated treatment effect. We therefore rely on three additional proxy measures less subject to this concern: (i) the number of votes cast for elite candidates; (ii) a dummy variable that equals 1 in every case where a candidate records enough votes to rank among the winning candidates at the polling substation, which we report in online Appendix A.2; and (iii) primary reports that materials were stolen or damaged by local candidate representatives. 36

\footnotetext{
${ }^{32}$ The survey contained 2,904 respondents. To obtain a representative sample of respondents living near polling centers, enumerators employed a random walk pattern starting at the polling center, with random selection of every fourth house or structure. Respondents within households are randomly selected using Kish grid. The survey had 50 percent male and female respondents each and enumerators conducted interviews in either Dari or Pashto.

${ }^{33}$ An alternative is to drop these 21 polling centers from specifications with district fixed effects reflecting the lack of baseline survey data to stratify them on. Results are robust to this change.

${ }^{34}$ Bruhn and McKenzie (2009) suggest stratifying treatment assignment on baseline measurements of key outcomes to increase power. Because measures of fraud are unavailable prior to the election, we select our stratifying variables by identifying measures most highly correlated with fraud during the 2009 presidential election in a national sample.

${ }^{35}$ Estimates in column 1 of Table 7 additionally indicate that treatment did not affect turnout.

${ }^{36}$ The number of votes cast for elite candidates is available for 461 of our 471 polling centers. Baseline covariates are not available for 21 of the 461 polling centers with vote outcome data. Specifications are therefore estimated on samples corresponding to 461 polling centers when control variables are not included and 440 when control variables are included. Specifications in Table 9 are estimated on one less polling center which we drop when trimming the top percentile of results. Only one polling center is dropped (rather than four), because there can be several powerful candidates in a given polling center.
} 
TABLE 4-RANDOMIZation Verification

\begin{tabular}{|c|c|c|c|c|c|c|}
\hline & $\begin{array}{l}\text { Control } \\
\text { (1) }\end{array}$ & $\begin{array}{c}\text { Treat } \\
(2)\end{array}$ & $\begin{array}{l}\mathrm{T}-\mathrm{C} \\
(3)\end{array}$ & $\begin{array}{c}p \text {-value } \\
(4)\end{array}$ & $\begin{array}{c}\text { Obs. } \\
\text { (Control) } \\
(5)\end{array}$ & $\begin{array}{c}\text { Obs. } \\
\text { (Treat) } \\
(6)\end{array}$ \\
\hline \multicolumn{7}{|l|}{ Baseline survey data } \\
\hline Plans to turnout during election $(=1)$ & $\begin{array}{c}0.790 \\
{[0.236]}\end{array}$ & $\begin{array}{c}0.797 \\
{[0.232]}\end{array}$ & $\begin{array}{c}0.008 \\
(0.022)\end{array}$ & 0.734 & 223 & 227 \\
\hline Believes vote is secret $(=1)$ & $\begin{array}{c}0.668 \\
{[0.265]}\end{array}$ & $\begin{array}{c}0.650 \\
{[0.255]}\end{array}$ & $\begin{array}{r}-0.018 \\
(0.024)\end{array}$ & 0.453 & 223 & 227 \\
\hline Candidate will know how I voted $(=1)$ & $\begin{array}{c}0.086 \\
{[0.146]}\end{array}$ & $\begin{array}{c}0.090 \\
{[0.153]}\end{array}$ & $\begin{array}{c}0.004 \\
(0.014)\end{array}$ & 0.767 & 223 & 227 \\
\hline Can identify sitting MP $(=1)$ & $\begin{array}{c}0.371 \\
{[0.325]}\end{array}$ & $\begin{array}{c}0.386 \\
{[0.318]}\end{array}$ & $\begin{array}{c}0.015 \\
(0.030)\end{array}$ & 0.627 & 223 & 227 \\
\hline $\begin{array}{l}\text { People in precinct will vote } \\
\quad \text { for same candidate }(=1)\end{array}$ & $\begin{array}{c}0.236 \\
{[0.253]}\end{array}$ & $\begin{array}{c}0.249 \\
{[0.258]}\end{array}$ & $\begin{array}{c}0.012 \\
(0.024)\end{array}$ & 0.607 & 221 & 224 \\
\hline $\begin{array}{l}\text { Problems with ballot transport } \\
\quad \text { are likely }(=1)\end{array}$ & $\begin{array}{c}0.538 \\
{[0.305]}\end{array}$ & $\begin{array}{c}0.534 \\
{[0.302]}\end{array}$ & $\begin{array}{r}-0.004 \\
(0.029)\end{array}$ & 0.880 & 219 & 225 \\
\hline Police in PC help security $(=1)$ & $\begin{array}{c}0.728 \\
{[0.246]}\end{array}$ & $\begin{array}{c}0.737 \\
{[0.241]}\end{array}$ & $\begin{array}{c}0.009 \\
(0.023)\end{array}$ & 0.701 & 223 & 227 \\
\hline $\begin{array}{l}\text { People like you are threatened to } \\
\text { vote one way }(=1)\end{array}$ & $\begin{array}{c}0.213 \\
{[0.231]}\end{array}$ & $\begin{array}{c}0.202 \\
{[0.223]}\end{array}$ & $\begin{array}{r}-0.011 \\
(0.021)\end{array}$ & 0.606 & 223 & 226 \\
\hline $\begin{array}{l}\text { Local violence likely on } \\
\text { election day }(=1)\end{array}$ & $\begin{array}{c}0.500 \\
{[0.316]}\end{array}$ & $\begin{array}{c}0.483 \\
{[0.347]}\end{array}$ & $\begin{array}{r}-0.017 \\
(0.031)\end{array}$ & 0.592 & 219 & 226 \\
\hline MP Candidate from same Qawm $(=1)$ & $\begin{array}{c}0.235 \\
{[0.219]}\end{array}$ & $\begin{array}{c}0.232 \\
{[0.227]}\end{array}$ & $\begin{array}{r}-0.003 \\
(0.021)\end{array}$ & 0.878 & 223 & 227 \\
\hline Trad. auth. helps settle disputes $(=1)$ & $\begin{array}{c}0.286 \\
{[0.267]}\end{array}$ & $\begin{array}{c}0.293 \\
{[0.240]}\end{array}$ & $\begin{array}{c}0.007 \\
(0.024)\end{array}$ & 0.785 & 223 & 227 \\
\hline Pashtun $(=1)$ & $\begin{array}{c}0.323 \\
{[0.388]}\end{array}$ & $\begin{array}{c}0.318 \\
{[0.407]}\end{array}$ & $\begin{array}{r}-0.005 \\
(0.037)\end{array}$ & 0.903 & 223 & 227 \\
\hline Tajik $(=1)$ & $\begin{array}{c}0.436 \\
{[0.387]}\end{array}$ & $\begin{array}{c}0.433 \\
{[0.390]}\end{array}$ & $\begin{array}{r}-0.004 \\
(0.037)\end{array}$ & 0.921 & 223 & 227 \\
\hline Income generating activity $(=1)$ & $\begin{array}{c}0.602 \\
{[0.197]}\end{array}$ & $\begin{array}{l}0.607 \\
{[0.192]}\end{array}$ & $\begin{array}{c}0.004 \\
(0.018)\end{array}$ & 0.817 & 223 & 227 \\
\hline Electrified $(=1)$ & $\begin{array}{c}0.722 \\
{[0.300]}\end{array}$ & $\begin{array}{c}0.706 \\
{[0.323]}\end{array}$ & $\begin{array}{r}-0.016 \\
(0.029)\end{array}$ & 0.595 & 223 & 227 \\
\hline $\begin{array}{l}\text { District Governor keeps } \\
\quad \text { election fair }(=1)\end{array}$ & $\begin{array}{c}0.112 \\
{[0.170]}\end{array}$ & $\begin{array}{c}0.114 \\
{[0.169]}\end{array}$ & $\begin{array}{c}0.003 \\
(0.016)\end{array}$ & 0.864 & 223 & 225 \\
\hline \multicolumn{7}{|l|}{ Administrative data } \\
\hline $\begin{array}{l}\text { Visited by international } \\
\text { election monitors }(=1)\end{array}$ & $\begin{array}{c}0.146 \\
{[0.353]}\end{array}$ & $\begin{array}{c}0.182 \\
{[0.385]}\end{array}$ & $\begin{array}{c}0.036 \\
(0.035)\end{array}$ & 0.308 & 223 & 227 \\
\hline $\begin{array}{l}\text { Visited by domestic } \\
\text { election monitors }(=1)\end{array}$ & $\begin{array}{c}0.892 \\
{[0.311]}\end{array}$ & $\begin{array}{c}0.863 \\
{[0.344]}\end{array}$ & $\begin{array}{r}-0.029 \\
(0.031)\end{array}$ & 0.350 & 223 & 227 \\
\hline $\begin{array}{l}\text { Indelible ink washes } \\
\quad \text { or not available }(=1) \text { (pre-treatment) }\end{array}$ & $\begin{array}{c}0.798 \\
{[0.402]}\end{array}$ & $\begin{array}{c}0.762 \\
{[0.427]}\end{array}$ & $\begin{array}{r}-0.036 \\
(0.039)\end{array}$ & 0.357 & 223 & 227 \\
\hline
\end{tabular}

Notes: This table checks balance between treatment and control polling centers. The unit of observation is the polling center. The first 16 rows report data from the baseline survey. In these 16 rows, each polling center observation reflects an average of responses from either six or eight respondents sampled in the immediate vicinity of the polling center. An observation is missing if all of the respondents in the polling center catchment refused to respond. The last three rows report administrative data. "Visited by international election monitors" is a dummy that equals 1 if a foreign observer from Democracy International visited the polling center. "Visited by domestic election monitors" is a dummy that equals 1 if an Afghan observer from Free and Fair Elections Afghanistan (FEFA) visited the polling center. "Indelible ink washes or not available" is a dummy that equals 1 if the indelible ink used to prevent individuals from voting multiple times exhibited either problem and is recorded by FEFA. Column 1 produces averages for the control sample, column 2 provides averages for the treatment sample, column 3 reports the difference of column 2 and column 1, and column 4 reports the $p$-value from a $t$-test of equality in means between control and treatment. Column 5 reports the number of observations in the control sample and column 6 reports the number in the treatment sample. Standard deviations are reported in brackets and standard errors are reported in parentheses.

***Significant at the 1 percent level. **Significant at the 5 percent level. * Significant at the 10 percent level. 


\section{A. Aggregation Fraud}

The purpose of our treatment was to provide incentives to election officials to ensure that no discrepancies arose during aggregation. Given this objective and our finding in Section II that votes are both commonly added and subtracted, we examine impacts on the absolute value of vote differences between pre-aggregation and post-aggregation vote totals. ${ }^{37}$ This measure exhibited a large degree of treatment-related attrition. We turn to a discussion of how we address this issue in our analysis.

Addressing Attrition.- Treatment significantly increased the availability of photographic records $(p=0.064)$, potentially biasing mean difference estimators of the treatment effect. ${ }^{38}$ In general, with substantial treatment-related attrition, the effect of treatment on fraud will be confounded with its effect on the availability of photographic records. The mean difference may only reflect treatment revealing an additional part of the fraud distribution, while there is no actual effect on the outcome of interest. To address this, we use the method provided in Lee (2009), which estimates bounds on the effect of treatment in the presence of nonrandom attrition. The purpose of this method is to trim observations that report outcomes only under treatment from the estimation sample, allowing impacts to be estimated using only units where outcomes would be observed irrespective of treatment assignment. ${ }^{39}$

This method relies fundamentally on the monotonicity assumption. ${ }^{40}$ In this setting, there are two ways that the attrition process could be monotonic. Both regard polling officials who would post Declarations of Results forms under treatment, but not otherwise. In the first instance, these marginal officials might respond to the treatment notification letter by posting results only in cases when doing so does not reveal fraud during the aggregation process. This implies that trimming the corresponding marginal polling substations from the bottom of the treatment sample provides the correct estimate. In the second, these officials might respond to treatment by posting results only in locations where there is substantial fraud. ${ }^{41}$ In this case, trimming the corresponding portion at the top of the treatment distribution provides the correct estimate. An intermediate scenario would arise if low-level polling center managers are unaware of aggregation fraud that takes place later in the aggregation process. In this case, the true effect would lie between the two bounds.

To illustrate this method, Table 5 applies the method to the absolute vote difference for candidates connected to the provincial aggregator. Of the 892 polling

\footnotetext{
${ }^{37}$ In online Appendix A.4 we provide evidence that both vote additions and subtractions are especially large for powerful candidates, motivating our use of the absolute value measure for these subsamples.

${ }^{38}$ We collected pictures of 204 (20 percent) of the 1,020 Declarations of Results forms that should have been posted at treatment polling centers and 143 (14.77 percent) of the 968 forms that should have been posted at control polling centers. The treatment effect is therefore -0.052 (standard error $=0.028)$.

${ }^{39}$ These estimands are therefore different from the average treatment effect across the entire experimental sample. We point interested readers to the Gerber and Green (2012) text, which provides a clear description of the Lee (2009) method.

${ }^{40}$ Let $r_{i}(T)$ denote whether an outcome is reported as a function of treatment status $(T \in\{0,1\})$. When $r_{i}(T)=1$ the outcome is observed and when $r_{i}(T)=0$ it is not. The monotonicity assumption states $r_{i}(1) \geq r_{i}(0)$ or $r_{i}(1) \leq$ $r_{i}(0)$ for all $i$.

${ }^{41}$ This could happen if polling center managers in the most fraud-affected polling centers are not afraid of revealing fraud.
} 
Table 5-Trimmed Estimates of Effect on Aggregation Fraud

(Sample: provincial aggregator connection $(=1)$ )

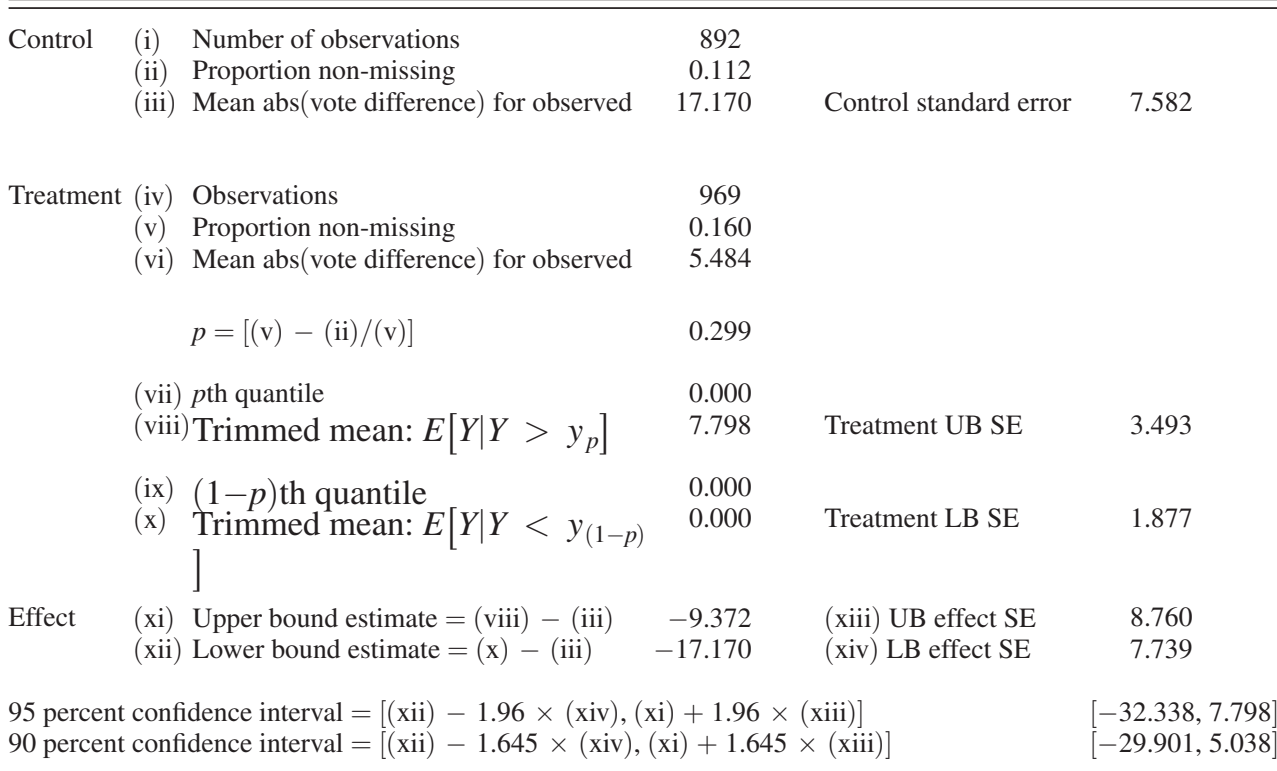

Notes: This table reports details of the Lee (2009) procedure applied to the data on aggregation fraud. The sample is all candidates with a recorded connection to the provincial aggregator. Rows (i)-(iii) provide values for the control group; rows (iv)-(vi) provide values for the untrimmed treatment group; rows (vii) and (viii) correspond to the treatment group after trimming the bottom $p$ percentiles; rows (ix) and (x) correspond to the treatment group after trimming the top $p$ percentiles. Rows (xi) and (xii) report the upper and lower bound respectively. The corresponding 95 percent and 90 percent confidence intervals are reported in the final two rows. There are 100 non-missing observations in the control group. Before trimming, there are 155 non-missing observations in the treatment group. After trimming, there are 109 (108) observations remaining in the treatment group after trimming the lower $p$ percentiles (the upper $p$ percentiles) of the distribution. Standard errors reported in this table are obtained by bootstrapping all polling centers in our experimental sample with replacement 250 times.

substations where we could potentially observe this measure in our control sample, we successfully measure 100 (11.2 percent). In this sample, the average absolute vote difference is 17.170. Turning to our treatment sample, there are 969 potential observations, of which we successfully measure 155 (16 percent). In this sample, the average absolute vote difference is 5.484.

To bound the treatment effect, we remove the part of the treatment group induced to reveal outcomes by treatment. We calculate the share to remove, the trimming ratio, as $\frac{16 \text { percent }-11.2 \text { percent }}{16 \text { percent }}=29.9$ percent. Under the monotonicity assumption, we can estimate the upper bound of the treatment effect (i.e., the smallest fraud reducing effect) by removing the bottom 29.9 percentiles in terms of absolute vote differences from the treatment sample and taking the difference between the trimmed treatment mean and the control mean. This yields an estimate of $7.798-17.170$ $=-9.372$ votes. To obtain the lower bound of the treatment effect (i.e., the largest fraud reducing effect), we remove the top 29.9 percentiles in terms of absolute vote differences. This yields an estimate of $0-17.170=-17.170$ votes ${ }^{42}$

\footnotetext{
${ }^{42}$ To construct confidence intervals, we estimate standard errors for both upper and lower bounds. Lee (2009) shows that the asymptotic variance of the trimming estimator depends on: (i) the variance of the trimmed outcome variable; (ii) the trimming threshold value, which is a quantile that must be estimated; and (iii) the corresponding trimming ratio, which is also estimated. Lee (2009), provides expressions for the asymptotic standard errors only
} 
Table 6-Trimmed Estimates of Effect on Aggregation Fraud

\begin{tabular}{|c|c|c|c|c|c|c|c|c|}
\hline & \multicolumn{2}{|c|}{ Control } & \multicolumn{4}{|c|}{ Treatment } & \multicolumn{2}{|c|}{ Treatment effect } \\
\hline & $\begin{array}{c}\text { Mean } \\
\text { post-aggreg. } \\
\text { votes } \\
(1)\end{array}$ & $\begin{array}{l}\text { Mean } \\
\text { abs. vote } \\
\text { diff. } \\
(2)\end{array}$ & $\begin{array}{l}\text { Mean } \\
\text { abs. vote } \\
\text { diff. } \\
(3)\end{array}$ & $\begin{array}{l}\text { Trimming } \\
\text { ratio } \\
(4)\end{array}$ & $\begin{array}{c}\text { Trimmed } \\
\text { mean } \\
E\left[Y \mid Y<y_{(1-p)}\right] \\
\quad(5)\end{array}$ & $\begin{array}{c}\text { Trimmed } \\
\text { mean } \\
E\left[Y \mid Y>y_{p}\right] \\
\quad(6)\end{array}$ & $\begin{array}{l}\text { Lower } \\
\text { bound } \\
(5)-(2)\end{array}$ & $\begin{array}{l}\text { Upper } \\
\text { bound } \\
(6)-(2)\end{array}$ \\
\hline \multicolumn{9}{|l|}{ Sample: } \\
\hline Full sample & 2.318 & $\begin{array}{l}0.817 * * * \\
(0.210)\end{array}$ & $\begin{array}{l}0.582 * * * \\
(0.140)\end{array}$ & 0.349 & $\begin{array}{c}0.000 \\
(0.245)\end{array}$ & $\begin{array}{l}0.893 * * * \\
(0.246)\end{array}$ & $\begin{array}{c}-0.817 * * \\
(0.342)\end{array}$ & $\begin{array}{c}0.076 \\
(0.249)\end{array}$ \\
\hline Incumbent & 7.501 & $\begin{array}{l}2.840 * * * \\
(0.801)\end{array}$ & $\begin{array}{l}1.597 * * * \\
(0.317)\end{array}$ & 0.308 & $\begin{array}{c}0.000 \\
(0.498)\end{array}$ & $\begin{array}{l}2.308 * * * \\
(0.572)\end{array}$ & $\begin{array}{l}-2.840 * * * \\
(0.981)\end{array}$ & $\begin{array}{c}-0.531 \\
(0.907)\end{array}$ \\
\hline $\begin{array}{l}\text { Most } \\
\text { connected } \\
\text { candidate }\end{array}$ & 24.739 & $\begin{array}{l}10.310^{*} \\
(5.476)\end{array}$ & $\begin{array}{l}3.799 * * * \\
(1.417)\end{array}$ & 0.265 & $\begin{array}{c}0.000 \\
(0.802)\end{array}$ & $\begin{array}{l}5.167 * * \\
(2.053)\end{array}$ & $\begin{array}{r}-10.310^{*} \\
(5.566)\end{array}$ & $\begin{array}{c}-5.143 \\
(5.938)\end{array}$ \\
\hline $\begin{array}{l}\text { Prov. + district } \\
\text { aggregator } \\
\text { connection }\end{array}$ & 36.161 & $\begin{array}{l}18.790 * * \\
(9.009)\end{array}$ & $\begin{array}{l}5.760 * * \\
(2.510)\end{array}$ & 0.295 & $\begin{array}{l}0.000 \\
(2.030)\end{array}$ & $\begin{array}{l}8.090^{* * *} \\
(4.089)\end{array}$ & $\begin{array}{c}-18.790 * * \\
(9.090)\end{array}$ & $\begin{array}{l}-10.700 \\
(10.340)\end{array}$ \\
\hline $\begin{array}{l}\text { Karzai } \\
\quad \text { connection }\end{array}$ & 21.484 & $\begin{array}{l}8.831 * * \\
(3.701)\end{array}$ & $\begin{array}{l}3.667 * * * \\
(1.049)\end{array}$ & 0.309 & $\begin{array}{c}0.000 \\
(0.675)\end{array}$ & $\begin{array}{l}5.282 * * * \\
(1.782)\end{array}$ & $\begin{array}{l}-8.831 * * \\
(3.772)\end{array}$ & $\begin{array}{c}-3.549 \\
(4.176)\end{array}$ \\
\hline $\begin{array}{l}\text { Government } \\
\text { service }\end{array}$ & 18.788 & $\begin{array}{l}9.665^{* * * *} \\
(3.139)\end{array}$ & $\begin{array}{l}5.126 * * * \\
(1.098)\end{array}$ & 0.291 & $\begin{array}{c}0.013 \\
(0.878)\end{array}$ & $\begin{array}{l}7.217 * * * \\
(1.899)\end{array}$ & $\begin{array}{l}-9.652 * * * \\
(3.277)\end{array}$ & $\begin{array}{r}-2.448 \\
(3.666)\end{array}$ \\
\hline
\end{tabular}

Notes: This table reports the details of calculating bounds for the treatment effect using the method of Lee (2009) for each candidate subsample. Note we only observe connections for candidates with background investigations data. The outcome variable is the absolute difference between pre-aggregation votes and post-aggregation votes. The unit of observation is the candidate-polling station. Each row provides results for the indicated candidate subsample. Column 1 reports the mean post-aggregation vote total in the controls. Columns 2, 3, 5, and 6 provide the means in the control, untrimmed treatment, treatment trimmed above the $(1-p)$ th percentile, and treatment trimmed below the $p$ th percentile respectively. Column 4 reports the trimming ratio. The last two columns report the lower and upper bounds on the treatment effect. The number of observations [proportion non-missing] for each control subsample are as follows. Full Sample: 183,660 [0.097], Incumbent: 10,492 [0.118], Most connected candidate 962 [0.148], Prov. + district aggregator connection: 441 [0.184], Karzai Connection 1,550 [0.141], Government Service 1,945 [0.143]. The number of observations [proportion non-missing] for each treatment subsample are as follows. Full Sample: 203,921 [0.149], Incumbent: 11,485 [0.171], Most Connected Candidate: 1,016 [0.201], Prov. + district aggregator connection: 480 [0.260] Karzai connection: 1,600 [0.204], Government service 2,089 [0.202]. Full details of these calculations are reported in online Appendix Tables A10 through A15. Standard errors obtained by bootstrapping polling centers 250 times with replacement are reported in parentheses.

*** Significant at the 1 percent level.

** Significant at the 5 percent level.

* Significant at the 10 percent level.

Table 6 summarizes estimates from the same exercise performed on the full sample, and for each of the remaining five candidate type subsamples. ${ }^{43}$ To provide a basis of comparison for the estimated effect sizes, column 1 reports the mean post-aggregation vote-total across candidate-polling substations for the controlling polling substations within the candidate subsample. Column 2 reports the mean vote difference in the observed control sample. These estimates are consistent with our finding in Table 3 above that observations corresponding to connected candidates are more likely to exhibit discrepancies. Column 3 reports the mean absolute vote difference in the untrimmed treatment sample. The next column provides the trimming ratio $p$. Column 5 provides the trimmed mean in the treatment sample trimming observations above the $(1-p)$ th percentile and column 6 reports the trimmed mean eliminating the bottom $p$ percentiles. The final two columns report the lower

for the i.i.d. case. Our treatment is administered at the cluster (polling center) level. Therefore, as in Vogl (2013), we block-bootstrap the bounds estimator at the polling center level.

${ }^{43}$ In online Table A4, we perform the same exercise using the simple vote difference as an outcome. We find no evidence of a mean effect on this outcome. In online Appendix A.4, we argue that this is because photo quick count appears to reduce rigging both for and against powerful candidates in roughly equal measure. We also provide evidence that the reason we find a post-aggregation reduction in Table 7 while finding no effect on vote differences may be because treatment affected the number of votes posted immediately after treatment. This is necessarily speculative because of the limited sample with vote difference data. Online Tables A10 through A15 replicate Table 5 for each of the five remaining subsamples. 
bound and the upper bound, respectively. In five of the six cases, the estimated upper bound is below zero. In no cases, however, can we statistically reject that the upper bound is different from zero.

Using the post-aggregation total in column 1 as a point of reference, the upper and lower bound estimates indicate that treatment reduces the vote discrepancy substantially. Looking at the upper bound (the smallest effect on fraud) for the most connected candidate suggests a vote discrepancy reduction of 20.1 percent. The upper bound for candidates connected to both the district and provincial aggregators suggests a reduction of nearly 30 percent.

\section{B. Votes for Elite Candidates}

We next estimate the impact of photo quick count on votes for elite candidates. This measure has the benefit of much less treatment-related attrition, but provides a less precise reflection of fraud than our picture-based measure. ${ }^{44}$ We obtained data on votes disaggregated by candidate and polling substation from a scrape of the election commission website on October 24, 2010. During the scrape, 98 of the 1,977 polling substations in our experimental sample (4.96 percent) had not yet posted returns. These 98 polling substations were contained within ten polling centers. Missing data are not predicted by treatment status $(p=0.439) .45$

We run regressions of the form

$$
\begin{aligned}
Y_{i s}= & \beta_{1}+\beta_{2} \text { Treat }_{s}+\beta_{3} \text { Treat }_{s} \times \text { Connection }_{i} \\
& +\beta_{4} \text { Treat }_{s} \times \text { Investigated }_{i}+\beta_{7}^{\prime} \mathbf{X}_{i s}+\varepsilon_{i s},
\end{aligned}
$$

where $Y_{i s}$ is votes cast for candidate $i$ in polling substation $s$, Connection Co $_{i}$ is dummy variable equal to 1 for candidates with a specific type of political connection, Investigated ${ }_{i}$ is a dummy variable equal to 1 for candidates with investigations data, and $\mathbf{X}_{i s}$ is a matrix containing covariates from our baseline survey, the Investigated $_{i}$ and Connected $_{i}$ dummies, and a set of stratum fixed effects.

To succinctly summarize impact, we also identify highly influential candidates using an index based on our political connections data. We identify one elite candidate in each of the 19 political constituencies by constructing the following index from the data on political connections described in Section II:

$$
\text { Index }_{i}=\text { Karzai }_{i}+\text { Government }_{i}+\mathrm{DEO}_{i}+\mathrm{PEO}_{i}
$$

$K_{a r z a i}$ equals 1 for a candidate $i$ with an indirect connection to Karzai (e.g., through a relative) and 2 for a direct connection (e.g., serving directly with the president), Government ${ }_{i}$ equals 1 for holding a minor government post since 2001 (e.g., teacher) and 2 for holding a major government post (e.g., parliamentarian),

\footnotetext{
${ }^{44}$ This approach follows the existing literature on the impact of election monitoring (Hyde 2007).

${ }^{45}$ Regressions reported in Tables 7 and 8 are estimated on a sample of 461 polling centers when control variables are not included and 440 polling centers when control variables are included. The reason for this is that we could not obtain voting outcomes for 10 of our 471 polling centers during the web scrape and we lack control variables for an additional 21 polling centers.
} 
$D E O_{i}$ equals 1 when connected to the District Elections Officer, and $P E O_{i}$ equals 1 when connected to the Provincial Elections Officer. We term the candidate with the highest index score who is also among the top ten vote recipients in control polling centers as the most connected candidate. Online Figure A3 depicts average votes in treatment and control polling centers for each type of candidate connection.

Column 1 of panel A of Table 7 reports the impact on treatment for all candidates, finding no evidence of effect across all candidates. Columns 2-5 provide estimated effects from regressions interacting treatment with an dummy variable equal to 1 for the most connected candidate using several different specifications. For all of these specifications, we find that the most connected candidate obtains about 17 to 20 votes at a given polling substation. In columns $2-4$ we see that treatment reduced votes for most connected candidates from an average of about 21 votes to about 15 votes (a reduction of about 25 percent). Column 5 reports estimates trimming the top percentile of votes for the interacted candidate type. The most connected candidates are typically among the very highest vote recipients. We trim to ensure that our effects are not driven by a few extreme outliers. Removing these observations both lowers the number of votes powerful candidates received in controls and reduces the estimated treatment effect by about one vote, though effects remain significant. As in column 1, there is no evidence of effect on the remaining candidates without recorded connections. This provides some evidence that the effect is localized to elite candidates, consistent with political connections playing a role in facilitating access to aggregation fraud.

Panel B of Table 7 reports results from regressions interacting treatment with specific candidate categories and a dummy for whether they are among the set of 57 candidates with background investigations data. The point estimates suggest a negative effect for all investigated candidates. The estimated joint effect of being investigated and having a connection are statistically different from zero at the 95 percent level for candidates with a provincial aggregator connection in column 1 and for candidates with a history of government service in column 3. As in panel A, there appears to be no effect on candidates without recorded connections and connected candidates obtain higher vote totals.

To benchmark the size of the impacts estimated in Table 7, online Appendix A.2 examines the impact of treatment on whether candidates score enough votes at a given polling substation to be ranked above the threshold required to obtain office in their constituency. Specifically, we estimate the effect of treatment on a dummy variable that equals 1 for every candidate-polling substation observation recording enough votes to rank among the winning candidates at the polling station. The largest effects are for candidates connected to the provincial aggregator (column 2 of online Table A2). These candidates have a 57 percent chance of ranking above the victory threshold in control polling stations. Point estimates indicate that treatment reduced the probability of winning by 11.5 percentage points. The degree of the reduction suggests that, for powerful candidates, aggregation fraud is severe enough to play a meaningful role in determining final election outcomes.

\section{Theft and Damaging of Forms}

On the day after the election, our field staff visited all 471 operating polling centers in the experimental sample. During the visit, they attempted to photograph returns 
Table 7-Estimates of Impact on Total Votes by Candidate Connection

\begin{tabular}{lccccc}
\hline \hline & \multicolumn{5}{c}{ Votes } \\
\cline { 2 - 6 } & $(1)$ & $(2)$ & $(3)$ & $(4)$ & $(5)$ \\
\hline Panel A. Impacts on most connected candidates & & & & & \\
Letter treatment (=1) & -0.066 & -0.034 & 0.030 & 0.019 & -0.033 \\
& $(0.212)$ & $(0.196)$ & $(0.045)$ & $(0.056)$ & $(0.054)$ \\
Treat $\times$ most connected & & $-5.430^{*}$ & $-5.392^{*}$ & $-5.780^{*}$ & $-4.634^{* *}$ \\
& & $(3.111)$ & $(3.080)$ & $(3.245)$ & $(2.347)$ \\
Most connected (=1) & & $20.871^{* * *}$ & $18.604^{* * *}$ & $19.746^{* * *}$ & $16.794^{* * *}$ \\
& & $(2.391)$ & $(2.364)$ & $(2.489)$ & $(1.787)$ \\
Constant & $1.410^{* * * *}$ & $1.301^{* * *}$ & $1.279^{* * *}$ & $1.952^{* * *}$ & $1.808^{* * *}$ \\
& $(0.156)$ & $(0.144)$ & $(0.032)$ & $(0.108)$ & $(0.106)$ \\
Stratum FEs & No & No & Yes & Yes & Yes \\
Full covariates & No & No & No & Yes & Yes \\
Trimming top 1 percent of votes for interacted candidate type & No & No & No & No & Yes \\
$R^{2}$ & 0.000 & 0.024 & 0.079 & 0.077 & 0.094 \\
Number polling centers & 461 & 461 & 461 & 440 & 440 \\
Number candidate-polling station observations & 386,855 & 386,855 & 386,855 & 309,947 & 309,822 \\
Mean of dep. var. in controls & 1.410 & 1.410 & 1.410 & 1.724 & 1.629 \\
Mean of dep. var. in controls for interacted connection & - & 22.172 & 22.172 & 23.516 & 20.170 \\
\hline & & & & & $($ Continued
\end{tabular}

forms. If the forms were missing, they investigated whether any of the materials had been stolen or damaged during the night of the election. ${ }^{46}$ Investigations involved interviewing residents living in the immediate vicinity of polling centers. ${ }^{47}$ In this section, we estimate impacts on forms reported as stolen or damaged by candidate agents, who are candidate proxies legally permitted to observe polling and are typically present at most polling centers in their candidate's constituency. Candidate agents are supporters of the candidate who play a crucial role assisting candidates at all stages of the campaign. Candidate agents stole or damaged materials at 62 (13.16 percent) of the 471 operating polling centers.

There are several reasons that stealing or damaging forms may reflect an intention to change vote totals during aggregation. Records of citizen and candidate complaints provided by the Electoral Complaints Commission indicate that the purpose of stealing forms was to take them to a separate location, alter them, and then reinsert them into the aggregation process. For example, at the Sayedullah Khan Bazaar high school in Terin Kot in Urozgan province, a candidate reports: "382 votes were cast, but then the voting papers were inexplicably lost. Later that evening, I observed the brother of a leading candidate replacing the vote papers into the boxes." Alternatively, candidates might seek to destroy all evidence of the polling center count, and then manufacture entirely new results forms. Correspondingly, an empowered polling center manager, who knows that the absence of forms will be

\footnotetext{
${ }^{46}$ These investigations produce 44 reports of candidate agents stealing the returns form along with the ballot boxes and other election materials, 18 reports of candidate agents merely tearing down the returns form, 15 reports of citizens stealing returns forms, 17 reports of citizens tearing down returns forms, and 28 reports of security officials stealing materials or denying our interviewers access to photograph them.

${ }^{47}$ While election commission staff should have vacated the polling center at the end of election day, we trained our staff to investigate by only interviewing local community members and not to engage commission staff so as to not create a measurement effect. While this would not affect the internal validity of our estimates of program effect, our aim was to minimize the additional monitoring effect for the entire sample. Results obtained with these data merit some caution as our field staff could only rely on reports of nearby citizens to determine the reason that Declaration of Results forms are missing.
} 
Table 7-Estimates of Impact on Total Votes by Candidate Connection (Continued)

\begin{tabular}{|c|c|c|c|c|c|}
\hline & \multicolumn{5}{|c|}{ Votes } \\
\hline & (1) & (2) & (3) & (4) & (5) \\
\hline \multicolumn{6}{|l|}{ Panel B. Impacts by connection type } \\
\hline Letter treatment $(=1)$ & $\begin{array}{r}-0.010 \\
(0.052)\end{array}$ & $\begin{array}{c}0.005 \\
(0.053)\end{array}$ & $\begin{array}{c}0.010 \\
(0.053)\end{array}$ & $\begin{array}{c}-0.011 \\
(0.052)\end{array}$ & $\begin{array}{c}-0.029 \\
(0.049)\end{array}$ \\
\hline Treat $\times$ investigated & $\begin{array}{c}-2.864^{*} \\
(1.473)\end{array}$ & $\begin{array}{c}-1.583 \\
(1.641)\end{array}$ & $\begin{array}{c}-2.831^{*} \\
(1.680)\end{array}$ & $\begin{array}{c}-1.065 \\
(2.711)\end{array}$ & $\begin{array}{c}-2.472 \\
(1.851)\end{array}$ \\
\hline Treat $\times$ provincial aggregator connection & & $\begin{array}{c}-4.896 \\
(3.312)\end{array}$ & & & \\
\hline Treat $\times$ prov. and district aggregator connection & & & $\begin{array}{c}-3.293 \\
(4.368)\end{array}$ & & \\
\hline Treat $\times$ government service & & & & $\begin{array}{c}-2.399 \\
(3.142)\end{array}$ & \\
\hline Treat $\times$ Karzai connection & & & & & $\begin{array}{c}0.567 \\
(2.302)\end{array}$ \\
\hline Provincial aggregator connection $(=1)$ & & $\begin{array}{l}5.930 \text { ** } \\
(2.635)\end{array}$ & & & \\
\hline Prov. and district aggregator connection $(=1)$ & & & $\begin{array}{c}5.168 \\
(3.539)\end{array}$ & & \\
\hline Government service $(=1)$ & & & & $\begin{array}{c}-0.541 \\
(2.276)\end{array}$ & \\
\hline Karzai connect. $(=1)$ & & & & & $\begin{array}{c}-3.323^{*} \\
(1.786)\end{array}$ \\
\hline Investigated $(=1)$ & $\begin{array}{l}15.788 * * * \\
(1.122)\end{array}$ & $\begin{array}{l}14.524 * * * \\
(1.186)\end{array}$ & $\begin{array}{l}15.993^{* * *} \\
(1.300)\end{array}$ & $\begin{array}{l}16.429 * * * \\
(1.951)\end{array}$ & $\begin{array}{l}15.958 * * * \\
(1.436)\end{array}$ \\
\hline Constant & $\begin{array}{l}1.667^{* * * *} \\
(0.105)\end{array}$ & $\begin{array}{l}1.732 * * * \\
(0.107)\end{array}$ & $\begin{array}{l}1.726 * * * \\
(0.106)\end{array}$ & $\begin{array}{l}1.669 * * * \\
(0.105)\end{array}$ & $\begin{array}{l}1.536^{* * * *} \\
(0.097)\end{array}$ \\
\hline Stratum FEs & Yes & Yes & Yes & Yes & Yes \\
\hline Full covariates & Yes & Yes & Yes & Yes & Yes \\
\hline Trimming top 1 percent of votes for interacted candidate type & Yes & Yes & Yes & Yes & No \\
\hline T 1 & 0.123 & 0.118 & 0.117 & 0.123 & 0.131 \\
\hline Number polling centers & 440 & 440 & 440 & 440 & 440 \\
\hline Number candidate-polling station observations & 309,843 & 309,893 & 309,900 & 309,852 & 309,699 \\
\hline Mean of dep. var. in controls & 1.639 & 1.673 & 1.677 & 1.646 & 1.562 \\
\hline Mean of dep. var. in controls for interacted connection & 18.713 & 24.147 & 24.834 & 18.723 & 15.312 \\
\hline$p$-value $-H_{0}:$ Treat $\times$ Investigated + Treat $\times$ Connection $=0$ & 0.052 & 0.031 & 0.141 & 0.047 & 0.201 \\
\hline
\end{tabular}

Notes: This table reports effects on post-aggregation vote totals by candidate connection. The unit of observation is the candidatepolling substation. Each column reports the results of an OLS regression where total post-aggregation votes is the dependent variable and dummy variables that equal 1 for treatment, when the candidate-polling substation observation has the indicated connection, when the candidate is investigated, and their interactions are the independent variables. Note that we only observe connections for investigated candidates. Panel A reports treatment effect for the most connected candidate. Please see the text for details on how the most connected candidate variable is computed. Column 1 reports a bivariate treatment regression with no interaction terms; column 2 reports the results when treatment is interacted with the most connected candidate; column 3 reports a similar regression with stratum fixed effects included; column 4 adds controls for the share of respondents reporting that they are Pashtun, Tajik, and whether the polling center was visited by international election monitors; column 5 trims the top percentile of the dependent variable. Panel B reports results interacting the treatment dummy with each of the candidate connection dummies. All regressions reported in panel B include stratum fixed effects, controls for the share of respondents reporting that they are Pashtun, Tajik, and whether the polling center was visited by international election monitors; and have the top percentile of the dependent variable trimmed. The number of candidate-polling substations observations change slightly because of duplicates values at the top percentile. The final two rows in panel A and in panel B report the mean of the dependent variable in the controls and in the controls among observations for the interacted candidate type. Robust standard errors clustered at the polling center level are reported in parentheses.

**** Significant at the 1 percent level.

** Significant at the 5 percent level.

* Significant at the 10 percent level.

photographically documented, might stand up to agents seeking to remove election materials. While we lack data to know specifically how this happens, a reduction in this measure may correspond to a reduction in fraud. Table 8 provides several specifications estimating effects on this measure. ${ }^{48}$ Estimates in column 1 of Table 8

${ }^{48}$ We constrain the sample to the 461 polling centers for which we have post-aggregation vote data used in Table 7. Impacts are virtually identical relaxing this constraint. 
TABLE 8-IMPACTS ON FoRM THEFT

\begin{tabular}{lccccccc}
\hline \hline & \multicolumn{7}{c}{ Election returns form damaged $(=1)$} \\
\cline { 2 - 7 } & OLS & OLS & OLS & $\begin{array}{c}\text { Logit } \\
(4)\end{array}$ & $\begin{array}{c}\partial y / \partial x \\
(4 \mathrm{~A})\end{array}$ & $\begin{array}{c}\text { Cond. log. } \\
(5)\end{array}$ & $\begin{array}{c}\partial y / \partial x \\
(5 \mathrm{~A})\end{array}$ \\
\hline Letter treatment $(=1)$ & $-0.108^{* * *}$ & $-0.111^{* * *}$ & $-0.110^{* * *}$ & $-0.975^{* * * *}$ & $-0.106^{* * *}$ & $-1.072^{* * *}$ & $-0.220^{* * *}$ \\
& $(0.032)$ & $(0.031)$ & $(0.032)$ & $(0.302)$ & $(0.032)$ & $(0.371)$ & $(0.058)$ \\
Constant & $0.189 * * *$ & $0.191 * * *$ & $0.211^{* * *}$ & $-1.013^{* * *}$ & & & \\
& $(0.026)$ & $(0.025)$ & $(0.078)$ & $(0.317)$ & & Yes \\
Stratum FEs & No & Yes & Yes & No & & Yes \\
Full covariates & No & No & Yes & Yes & & {$[-88.087]$} \\
$R^{2}[$ log-likelihood] & 0.025 & 0.218 & 0.228 & {$[-165.651]$} & 440 & 249 \\
Observations & 461 & 461 & 440 & 440 & & \\
\hline
\end{tabular}

Notes: This table reports on the damaging of election returns form by treatment group. The unit of observation is the polling center. Columns 1 report results from an OLS regression where a dummy variable that is equal to 1 if any forms were damaged at the polling center is the dependent variable and a dummy variable equal to 1 for treatment polling centers is the independent variable. Column 2 adds stratum fixed effects. Column 3 adds controls for the share of respondents reporting that they are Pashtun, Tajik, and whether the polling center was visited by international election monitors. Column 4 reports a logit specification using the same dependent and independent variables as column 3. Column $4 \mathrm{~A}$ reports the marginal effect corresponding to column 4 . Column 5 reports a conditional logit fixed effects regression. One hundred ninety-one polling centers are dropped from this specification as within 32 of the strata there is no variation in the dependent variable. Column $5 \mathrm{~A}$ reports the marginal effect corresponding to column 5 . Robust standard errors are reported in parentheses.

*** Significant at the 1 percent level.

** Significant at the 5 percent level.

* Significant at the 10 percent level.

are that the effect of treatment was to reduce this specific type of theft from 18.9 percent in controls to about 8 percent in controls (a reduction of 60 percent). These estimates are robust to adjusting specifications to include stratum fixed effects (column 2), stratum fixed effects and covariates (column 3), estimation using logit (column 4) and conditional fixed effects logit (column 5).

\section{Tests for Spatial Externalities}

We next test for spatial externalities. We do this for four reasons. First, treatment externalities may confound our estimates of program effect, leading us to overstate impact if fraud is merely displaced and to understate impact if fraud is reduced in neighboring polling centers because of a chilling effect (Miguel and Kremer 2004). ${ }^{49}$ Second, displacement effects and chilling effects should be factored in when considering the efficacy of photo quick count. ${ }^{50}$ Third, tests for spatial externalities can provide some information about how aggregation fraud is perpetrated. Fourth, the estimated externalities, which indicate that monitoring announcements have negative effects on fraud in neighboring polling centers, provide additional evidence of a high elasticity of fraud with respect to the threat of monitoring.

\footnotetext{
${ }^{49}$ Because candidates run at large within a province, they may attempt substitution of legitimate and fake ballots anywhere within a province. Announcing monitoring in any polling center may therefore create treatment externalities for other polling centers in a province. In practice, however, candidates may face limits to displacing votes across polling substations within a province. Candidates mostly garner their votes in their home districts or towns where they remain popular, or from pockets of spatially clustered family members. For example, given the extreme ethnic segregation of neighborhoods in Afghanistan, a Tajik candidate receiving a considerable number of votes in a solidly Pashtun part of a province could raise immediate suspicions of fraud.

${ }^{50}$ Ichino and Schündeln (2012) find evidence that domestic observers monitoring the voter registration process during the 2008 election in Ghana displaced some irregularities to unmonitored electoral areas.
} 
The tests in this section are necessarily speculative. An ideal design allows an explicit comparison between various treatment densities against a set of pure controls. We could not achieve this for several reasons. For example, we could not treat rural polling centers, which comprise the majority of polling centers, due to safety concerns. 51

A simple, but imperfect, test for externalities is to compare votes for the most connected candidate in control polling substations which have no treated neighbors within a two-kilometer halo $(N=196)$ and in the remaining set of controls which have some treated neighbors within two kilometers $(N=704)$. We find that the average number of votes for the most connected candidates in the first group (42.939) is much larger than in the remaining controls (17.784) and that this difference is statistically significant $(p=0.004$, clustering standard errors at the polling center level). This suggests a negative treatment externality.

To examine this further, we estimate treatment externalities with the specification

$$
\begin{aligned}
Y_{i c s}= & \varphi_{1}+\varphi_{2} \text { Letter Treatment }_{c}+\varphi_{3} \text { Treated }_{c}^{1 k m}+\varphi_{4} \text { Total }_{c}^{1 k m} \\
& +\varphi_{5} \text { Treated }_{c}^{1-2 k m}+\varphi_{6} \text { Total }_{c}^{1-2 k m}+\varphi_{7}^{\prime} \mathbf{X}_{c}+\eta_{i c s} .
\end{aligned}
$$

$Y_{i c s}$ is the number of votes for the most connected candidate $i$ in polling substation $s$ in polling center $c$, Treated ${ }_{c}^{1 \mathrm{~km}}$ is a dummy equal to 1 if any neighbors of polling center $c$ within one kilometer are treated, Total $_{c}^{1 \mathrm{~km}}$ is the total number of polling centers within a one-kilometer halo, and variables are similarly defined for polling centers between one and two kilometers away. As in Miguel and Kremer (2004), our identifying assumption is that, conditional on the number of polling centers within a fixed halo, the number treated is random. Table A9 reports tests verifying this identifying assumption. ${ }^{52}$ We additionally estimate several variants of Specification 4 , providing the full set of interactions with Letter Treatment and separating Treated ${ }_{c}^{1 \mathrm{~km}}$ into a set of five dummy variables to test for nonlinear effects in local treatment saturations. ${ }^{53}$ Online Table A5 provides summary statistics for the data used in this analysis.

To assess the extent to which externalities confound our estimates of program effect, the first column of Table 9 estimates impact only for the most connected candidate for comparison with columns $2-4$, which control for spatial externalities. The estimate increases slightly when controlling for spatial externalities, but remains around four fewer votes for the most connected candidate. ${ }^{54}$ Column 2 provides

\footnotetext{
${ }^{51}$ Additionally, with only 34 electoral constituencies, the Afghan electoral system affords limited power for tests that vary treatment saturations at the constituency level.

${ }^{52}$ We check this assumption by estimating Specification 4, replacing the dependent variable with the same baseline variables that we use to test for treatment assignment balance in Table 4.

${ }^{53}$ In our data, the maximum number of polling centers within a one-kilometer radius is five, so we create categorical dummies for one treatment polling center within one kilometer, two treatment polling centers within one kilometer, and so on.

${ }^{54}$ The small change in the estimates of core impact despite large negative externalities in neighboring polling centers may be because own-treatment status is weakly correlated with the treatment status of nearby polling centers. To see this, imagine we estimate only $y_{c}=\beta T_{c}^{\text {own }}+\eta_{c}$, when $y_{c}=\beta T_{c}^{\text {own }}+\gamma T_{c}^{\text {neighbor }}+\epsilon_{c}$ is the true model and $\operatorname{cov}\left(T_{c}^{o w n}, T_{c}^{\text {neighbor }}\right) \approx 0$. Then, since by a standard result $E[\hat{\beta}]=\beta+\operatorname{cov}\left(T_{c}^{\text {own }}, T_{c}^{\text {neighbor }}\right) \gamma, E[\hat{\beta}] \approx \beta$, even when $\gamma$ is large. Intuitively, this is equivalent to saying that there are a large number of valid controls mixed in with the contaminated controls.
} 
Table 9-Spatial Treatment Externalities

\begin{tabular}{|c|c|c|c|c|}
\hline & \multicolumn{4}{|c|}{ Votes for the most connected candidate } \\
\hline & (1) & (2) & (3) & (4) \\
\hline Letter treatment $(=1)$ & $\begin{array}{c}-4.080 * * \\
(2.009)\end{array}$ & $\begin{array}{c}-4.183^{* *} \\
(1.982)\end{array}$ & $\begin{array}{c}-4.290 * * \\
(1.956)\end{array}$ & $\begin{array}{c}-4.159^{* *} \\
(1.980)\end{array}$ \\
\hline Any PCs treated within $1 \mathrm{~km}(=1)$ & & $\begin{array}{r}-6.877 * \\
(3.512)\end{array}$ & $\begin{array}{c}-6.742 * \\
(3.486)\end{array}$ & \\
\hline Total PCs within $1 \mathrm{~km}$ & & $\begin{array}{r}-0.597 \\
(0.566)\end{array}$ & $\begin{array}{r}-0.499 \\
(0.564)\end{array}$ & $\begin{array}{r}-1.256 \\
(0.806)\end{array}$ \\
\hline Any PCs treated within $1-2 \mathrm{~km}(=1)$ & & & $\begin{array}{c}-4.738 \\
(4.244)\end{array}$ & $\begin{array}{c}-4.681 \\
(4.240)\end{array}$ \\
\hline Total PCs within $1-2 \mathrm{~km}$ & & & $\begin{array}{c}0.103 \\
(0.378)\end{array}$ & $\begin{array}{c}0.223 \\
(0.392)\end{array}$ \\
\hline 1 treated $\mathrm{PC}$ within $1 \mathrm{~km}(=1)$ & & & & $\begin{array}{c}-6.457^{*} \\
(3.613)\end{array}$ \\
\hline 2 treated PCs within $1 \mathrm{~km}(=1)$ & & & & $\begin{array}{c}-5.831 \\
(3.882)\end{array}$ \\
\hline 3 treated PCs within $1 \mathrm{~km}(=1)$ & & & & $\begin{array}{c}-3.007 \\
(4.858)\end{array}$ \\
\hline 4 treated PCs within $1 \mathrm{~km}(=1)$ & & & & $\begin{array}{c}1.459 \\
(5.620)\end{array}$ \\
\hline 5 treated PCs within $1 \mathrm{~km}(=1)$ & & & & $\begin{array}{r}-1.334 \\
(6.929)\end{array}$ \\
\hline Constant & $\begin{array}{l}28.064 * * * \\
(6.017)\end{array}$ & $\begin{array}{l}30.543 * * * \\
(6.043)\end{array}$ & $\begin{array}{l}32.378 * * * \\
(7.004)\end{array}$ & $\begin{array}{l}32.697 * * * \\
(6.987)\end{array}$ \\
\hline$R^{2}$ & 0.276 & 0.290 & 0.292 & 0.294 \\
\hline Trimming top 1 percent of votes for interacted candidate type & Yes & Yes & Yes & Yes \\
\hline Number polling centers & 439 & 439 & 439 & 439 \\
\hline Number candidate-polling substation observations & 1,841 & 1,841 & 1,841 & 1,841 \\
\hline Mean dep. var. control + no treated PCs $0-2 \mathrm{~km}$ & 42.939 & 42.939 & 42.939 & 42.939 \\
\hline
\end{tabular}

Notes: Each column provides results from an OLS regression of the post-aggregation vote total for the most connected candidate on a treatment dummy and variables to account for the number of neighboring polling centers that received treatment. These are: any polling center $(\mathrm{PC})$ treated within $1 \mathrm{~km}(2 \mathrm{~km})$ is a dummy variable that equals 1 if polling center within a 1 kilometer ( 2 kilometers) radius received a treatment notification letter; any PCs within $1 \mathrm{~km}(1-2 \mathrm{~km})$ is a variable equal to the number of polling centers within a 1 kilometer radius (1 to 2 kilometer radius) received a treatment notification letter; 1 treated $\mathrm{PC}$ within $1 \mathrm{~km}$ is a dummy that equals 1 if one polling center within a $1 \mathrm{~km}$ radius was treated and so on for two to five polling centers. The maximum number of polling centers treated within a kilometer in our sample is five. The unit of observation is the candidate-polling substation. The sample is restricted to the most connected candidate only. The most connected candidate is identified using the procedure described in Section IV. The top percentile is trimmed and stratum fixed effects and controls for the share of respondents reporting that they are Pashtun, Tajik, and whether the polling center was visited by international election monitors are included in all specifications. Robust standard errors clustered at the polling center level reported in parentheses.

*** Significant at the 1 percent level.

** Significant at the 5 percent level.

* Significant at the 10 percent level.

evidence of a negative externality, consistent with a chilling effect. The estimates in column 3 suggest that having a neighbor treated within one kilometer has a stronger negative externality ( -6.74 votes) than having a neighbor treated between one and two kilometers away ( -4.74 votes). Column 4 separates out the effects by the number of neighbors treated. Estimates here are imprecise, but they are consistent with treatment externalities decreasing in the number of neighbors treated. 55

\footnotetext{
${ }^{55}$ This pattern suggests that polling center managers both actively communicate with one another about external monitoring and that they may be sensitive to changes in the degree of monitoring. These communications may play
} 


\section{Conclusion}

Our results demonstrate that aggregation fraud represents a threat to electoral fairness and that photo quick count provides a means of addressing this problem. Our data provide, to our knowledge, the first direct measurement of aggregation fraud and also the first systematic evidence of candidates using their political networks to infiltrate electoral institutions. We discuss three direct policy implications and three broader implications for electoral competition. We conclude with directions for future research.

Our data yield three actionable policy results. First, photo quick count is effective, scalable, well-suited to citizen-based implementation and viral adoption, and is cost-effective relative to traditional international election monitoring. ${ }^{56}$ We successfully visited 471 polling centers, with a total budget of just over US\$100,000. 57 By contrast, the largest foreign mission during this election reached about 85 polling centers, spanning a smaller physical area than in our sample, with a budget of approximately US\$10 million. ${ }^{58}$ Moreover, as cellular networks densify and bandwidth increases, the potential for photo quick count to scale should expand and costs should decrease. Importantly, this approach may also be sustainable with limited international support. The need for similar interventions is likely to increase as developed countries transition to a light footprint approach to international engagement. Second, no matter how it is addressed, aggregation fraud appears to be a serious problem. Estimating the impact of aggregation fraud relative to other types of fraud lies beyond our data. Nonetheless, the sheer magnitude of the problem and the centrality of vote aggregation to the electoral process suggest that future efforts to improve elections should target this issue. Last, improving the independence of electoral institutions and ensuring that candidates cannot infiltrate them is necessary to achieve fair elections.

Aggregation fraud, in our data, is both prevalent and disproportionately beneficial to connected candidates. This has at least three negative implications for electoral competition. First, this creates a substantial barrier to entry for unconnected candidates. We find evidence that powerful candidates can both add votes for themselves and subtract votes for contenders. In this situation, competitors without connections may be at a serious disadvantage. In extreme cases, they may not be able to win at all without these connections, regardless of their competence. Second, candidates have incentives to cultivate connections in order to win elections. This may create reasons for candidates to favor clientelistic strategies relative to programmatic ones.

some role in shaping managers' beliefs about the probability that their results will be audited. The diminishing pattern is consistent with updating being greatest in response to the arrival of the first letter in a neighborhood.

${ }^{56}$ Viral adoption refers to the adoption of new technology by independent actors based on widely available information. Since completing our study, civil society groups in several countries have begun to implement photo quick count. For example, during the 2014 Afghan Presidential Election, the method was used to measure aggregation fraud at 80 percent of active polling centers.

${ }^{57}$ Costs were contained primarily because we used local staff. Photo quick count can be implemented as effectively by local staff without any special training by international election monitoring experts.

${ }^{58}$ Along these lines, the European Union spends approximately US\$4 million on an average election observation mission (European Union 2006). During the 2003 Cambodian National Assembly election, the European Union spent approximately US\$1.5 million to deploy 120 observers (López-Pintor and Fischer 2005). To our knowledge, the European Union and the Asia Foundation are the only major international election monitoring organizations that publish data on the cost of their missions. 
Last, the prevalence of aggregation fraud fundamentally limits the ability of voters to express their preferences through the ballot. The candidate who wins may be the one with the strongest connections, not the one preferred by voters. This would limit the disciplining role of elections.

Our findings produce a set of questions for future research. First, do informal connections between state actors explain corruption and accountability failures in other settings, such as state service provision? Second, a natural extension of this research involves investigating the longer term effects of fraud reduction on the effectiveness of government in improving social welfare and on citizens' attitudes toward government - an important consideration in states where government legitimacy is contested. Third, our paper suggests further work on institutional reforms that might improve the effectiveness and sustainability of government monitoring efforts. Finally, and perhaps more practically, our results suggest that identifying and operationalizing innovative uses of technology to quickly gather information on corruption, waste, and abuse is a promising direction for research and for policy.

\section{REFERENCES}

Aker, Jenny C., Paul Collier, and Pedro C. Vicente. 2013. "Is Information Power: Using Cellphones During an Election in Mozambique." Unpublished.

Beber, Bernd, and Alexandra Scacco. 2012. "What the Numbers Say: A Digit-Based Test for Election Fraud Using New Data from Nigeria." Political Analysis 20 (2): 211-34.

Berman, Eli, Jacob N. Shapiro, and Joseph H. Felter. 2011. "Can Hearts and Minds Be Bought? The Economics of Counterinsurgency in Iraq." Journal of Political Economy 119 (4): 766-819.

-Bertrand, Marianne, Simeon Djankov, Rema Hanna, and Sendhil Mullainathan. 2007. "Obtaining a Driver's License in India: An Experimental Approach to Studying Corruption.” Quarterly Journal of Economics 122 (4): 1639-76.

Besley, Timothy, and Robin Burgess. 2002. "The Political Economy of Government Responsiveness: Theory and Evidence from India." Quarterly Journal of Economics 117 (4): 1415-51.

Besley, Timothy, Rohini Pande, and Vijayendra Rao. 2005. "Participatory Democracy in Action: Survey Evidence from South India.” Journal of the European Economic Association 3 (2-3): 648-57.

-Besley, Timothy, and Torsten Persson. 2011. "The Logic of Political Violence." Quarterly Journal of Economics 126 (3): 1411-45.

Bruhn, Miriam, and David McKenzie. 2009. "In Pursuit of Balance: Randomization in Practice in Development Field Experiments.” American Economic Journal: Applied Economics 1 (4): 200-32.

-Cadot, Olivier. 1987. "Corruption as a Gamble." Journal of Public Economics 33 (2): 223-44.

Callen, Michael, and James D. Long. 2015. "Institutional Corruption and Election Fraud: Evidence from a Field Experiment in Afghanistan: Dataset." American Economic Review. http://dx.doi. org/10.1257/aer.20120427.

Callen, Michael, and Nils B. Weidmann. 2013. "Violence and Election Fraud: Evidence from Afghanistan.” British Journal of Political Science 43 (1): 53-75.

Cameron, A. Colin, Jonah B. Gelbach, and Douglas L. Miller. 2011. "Robust Inference With Multiway Clustering." Journal of Business \& Economic Statistics 29 (2): 238-49.

Chattopadhyay, Raghabendra, and Esther Duflo. 2004. "Women as Policy Makers: Evidence from a Randomized Experiment in India.” Econometrica 72 (5): 1409-43.

Di Tella, Rafael, and Ernesto Schargrodsky. 2003. "The Role of Wages and Auditing during a Crackdown on Corruption in the City of Buenos Aires." Journal of Law and Economics 46 (1): 269-92.

Duflo, Esther, Rema Hanna, and Stephen P. Ryan. 2012. "Incentives Work: Getting Teachers to Come to School." American Economic Review 102 (4): 1241-78.

Estok, Melissa, Neil Nevitte, and Glenn Cowan. 2002. The Quick Count and Election Observation. Washington, DC: National Democratic Institute for International Affairs.

European Union External Action. 2006. "European Union: External Action FAQ." http://www.eeas. europa.eu (accessed September 8, 2013).

Ferraz, Claudio, and Frederico Finan. 2008. "Exposing Corrupt Politicians: The Effects of Brazil's Publicly Released Audits on Electoral Outcomes." Quarterly Journal of Economics 123 (2): 703-45. 
-Ferraz, Claudio, and Frederico Finan. 2011. "Electoral Accountability and Corruption: Evidence from the Audits of Local Governments." American Economic Review 101 (4): 1274-311.

Fisman, Raymond. 2001. "Estimating the Value of Political Connections." American Economic Review 91 (4): 1095-102.

Fujiwara, Thomas. 2013. "Voting Technology, Political Responsiveness, and Infant Health: Evidence from Brazil." Unpublished.

Gerber, Alan S., and Donald P. Green. 2012. Field Experiments: Design, Analysis, and Interpretation. New York: W.W. Norton \& Company.

Hyde, Susan D. 2007. "The Observer Effect in International Politics: Evidence from a Natural Experiment." World Politics 60 (1): 37-63.

-Ichino, Nahomi, and Matthias Schündeln. 2012. "Deterring or Displacing Electoral Irregularities? Spillover Effects of Observers in a Randomized Field Experiment in Ghana." Journal of Politics 74 (1): 292-307.

Khwaja, Asim Ijaz, and Atif Mian. 2005. "Do Lenders Favor Politically Connected Firms? Rent Provision in an Emerging Financial Market.” Quarterly Journal of Economics 120 (4): 1371-411.

Lee, David S. 2009. "Training, Wages, and Sample Selection: Estimating Sharp Bounds on Treatment Effects." Review of Economic Studies 76 (3): 1071-102.

López-Pintor, Rafael, and Jeff Fischer. 2005. Cost of Registration and Elections (CORE) Project. Washington, DC: Center for Transitional and Post-Conflict Governance.

Martinez-Bravo, Monica, Gerard Padró i Miquel, Nancy Qian, and Yang Yao. 2013. "Elections and Economic Policy: Evidence from Rural China.” Unpublished.

McChrystal, Stanley. 2009. "COMISAF's Initial Assessment to the Secretary of Defense." Secretary of Defense Memorandum. August 30, 2009.

McGee, Rosie, and John Gaventa. 2011. "Shifting Power? Assessing the Impact of Transparency and Accountability Initiatives.” Institute of Development Studies Working Paper 383.

Mebane, Walter R. Jr. 2008. "Election Forensics: The Second-Digit Benford's Law Test and Recent American Presidential Elections." In Election Fraud: Detecting and Deterring Electoral Manipulation, edited by R. Michael Alvarez, Thad E. Hall, and Susan D. Hyde, 162-81. Washington, DC: The Brookings Institution.

Miguel, Edward, and Michael Kremer. 2004. "Worms: Identifying Impacts on Education and Health in the Presence of Treatment Externalities." Econometrica 72 (1): 159-217.

Myagkov, Mikhail, Peter C. Ordeshook, and Peter Shakin. 2009. The Forensics of Election Fraud: Russia and Ukraine. New York: Cambridge University Press.

National Democratic Institute. 2010. “Afghanistan Election Data.” http://2010.afghanistanelectiondata.org (accessed September 8, 2013).

Niehaus, Paul, Antonia Atanassova, Marianne Bertrand, and Sendhil Mullainathan. 2013. "Targeting with Agents." American Economic Journal: Economic Policy 5 (1): 206-38.

Olken, Benjamin A. 2007. "Monitoring Corruption: Evidence from a Field Experiment in Indonesia." Journal of Political Economy 115 (2): 200-49.

Olken, Benjamin A., and Patrick Barron. 2009. "The Simple Economics of Extortion: Evidence from Trucking in Aceh.” Journal of Political Economy 117 (3): 417-52.

Olken, Benjamin A., and Rohini Pande. 2011. "Corruption in Developing Countries.” National Bureau of Economic Research Working Paper 17398.

Pande, Rohini. 2003. "Can Mandated Political Representation Increase Policy Influence for Disadvantaged Minorities? Theory and Evidence from India." American Economic Review 93 (4): 1132-51.

Rashid, Ahmed. 2009. Descent into Chaos: The U.S. and the Disaster in Pakistan, Afghanistan, and Central Asia. London: Penguin Group.

Rose-Ackerman, Susan. 1975. "The Economics of Corruption." Journal of Public Economics 4 (2): 187-203.

-Shleifer, Andrei, and Robert W. Vishny. 1993. "Corruption.” Quarterly Journal of Economics 108 (3): 599-617.

Svensson, Jakob. 2003. "Who Must Pay Bribes and How Much? Evidence from a Cross Section of Firms." Quarterly Journal of Economics 118 (1): 207-30.

United States Army. 2006. "Field Manual 3-24: Counterinsurgency." Washington, DC: Department of the Army.

-Vogl, Tom S. 2013. "Marriage Institutions and Sibling Competition: Evidence from South Asia." Quarterly Journal of Economics 128 (3): 1017-72.

The World Bank. 2011. World Development Report 2011: Conflict, Security, and Development. Washington DC: The World Bank.

-Yang, Dean. 2008. "Can Enforcement Backfire? Crime Displacement in the Context of Customs Reform in the Philippines." Review of Economics and Statistics 90 (1): 1-14. 